Elsevier Editorial System(tm) for Fuel Manuscript Draft

Manuscript Number: JFUE-D-15-00827R2

Title: High-speed imaging of $\mathrm{OH}$ and acetone PLIF reveals the structure of methane inverse diffusion flames

Article Type: Original Research Paper

Keywords: inverse methane diffusion flame; high speed imaging; flame structure.

Corresponding Author: Dr. Ayman Moustafa Elbaz, Ph.D.

Corresponding Author's Institution: Clean Combustion Research Center

First Author: Ayman Moustafa Elbaz, Ph.D.

Order of Authors: Ayman Moustafa Elbaz, Ph.D.; William Roberts

Abstract: Most previous work on inverse diffusion flames (IDFs) has focused on laminar IDF emissions and the soot formation characteristics. Here, we investigate the characteristics and structure of methane IDFs using high speed planar laser-induced fluorescence (PLIF) images of $\mathrm{OH}$, particle image velocimetry (PIV), and acetone PLIF imaging for nonreacting cases. First, the flame appearance was investigated with fixed methane loading (mass flux) but with varying airflow rates, yielding a central air jet Reynolds number (Re) of 1,000 to 6,000 (when blow-off occurs). Next, it was investigated a fixed central air jet $\operatorname{Re}$ of 4500, but with varied methane mass flux such that the global equivalence ratio spanned 0.5 to 4. It was observed that at Re smaller than 2000, the inner air jet promotes the establishment of an inverse diffusion flame surrounded by a normal diffusion flame. However, when the Re was increased to 2500, two distinct zones became apparent in the flame, a lower entrainment zone and an upper mixing and combustion zone. $10 \mathrm{KHz}$ OH-PLIF images, and 2D PIV allow the identification of the fate and spatial flame structure. Many flame features were identified and further analyzed using simple but effective image processing methods, where three types of structure in all the flames investigated here: flame holes or breaks; closures; and growing kernels. Insights about the rate of evolution of these features, the dynamics of local extinction, and the sequence of events that lead to re-ignition are reported here. In the lower entrainment zone, the occurrence of the flame break events is counterbalanced by closure events, and the edge propagation appears to control the rate at which the flame holes and closures propagate. The rate of propagation of holes was found to be statistically faster than the rate of closure. As the flames approach blow-off, flame kernels become the main mechanism for flame re-ignition further downstream. The simultaneous OH-PLIF/Stereo PIV measurements indicate that the individual breaks events could be correlated to local vortical flow structure and strain rates fields. The detailed measurements provide a more complete understanding of IDF flame characteristics and structure than was previously possible. 



\section{Dear Prof.}

I am enclosing here with a manuscript entitled "High-speed imaging of $\mathrm{OH}$ and acetone PLIF reveals the structure of methane inverse diffusion flames" for evaluation. With the submission of this manuscript, I would like to undertake that the above mentioned manuscript has not been published elsewhere, accepted for publication elsewhere or under editorial review for publication elsewhere.

\section{Sincerely yours,}

Ayman elbaz on behalf of the authors

Corresponding author: Ayman Elbaz, Scientist, Clean Combustion Research Center, CCRC, King Abdullah Uiniversity of Science and Technology, KAUST.

e-mail: ayman.elhagrasy@kaust.edu.sa 
October 16, 2015

Professor: John William Patrick

Principal Editor

Fuel

Subject: Fuel Journal,

Manuscript: High-speed imaging of $\mathrm{OH}$ and acetone PLIF reveals the structure of methane inverse diffusion flames. Ref: JFUE-D-15-00827R1

Authors: Ayman Moustafa Elbaz, William Roberts

Dear Prof. John Patrick:

Thank you for accepting revising our paper and we appreciate the efforts of the reviewers. They have carefully critiqued our manuscript and provided important comments to improve the work. We have considered all their comments and responded by modifying the manuscript. We believe the revised manuscripts is a considerable improvement and suitable for publication in FUEL.

In the attached pages, we indicate the changes to the paper in response to the reviewers' comments. The reviewers' comments are given in red italic and our response is directly following. The changes in the manuscript are indicated in underline red text.

I appreciate your efforts with regard to the manuscript.

Best Regards,

Ayman M. Elbaz

Research Scientist,PhD.

Clean Combustion Research Center, KAUST

Building 5, Level four, 4216-Ws18

Cell:0544701524

Office: 8084625 


\section{Response to Reviewer 2:}

Reviewer \#2: It is grateful to note that the authors have responded to all the reviewers' comments and revised the manuscript accordingly in the correct direction. Overall, quality of the paper has been improved. However, there are still some issues for further consideration:

1> The title, in its present form, is appeared as a sentence, which needs to be revised as using sentence as title is rare and unusual.

- We introduce a new title which is more common to this measurments the title will be: "Experimental study of the inverse diffusion flame using high repetition rate $\mathrm{OH}$ /acetone PLIF and PIV" instead of" High-speed imaging of $\mathrm{OH}$ and acetone PLIF reveals the structure of methane inverse diffusion flames".

2> There are still some grammatical and typo errors in the manuscript.

- The paper is reviewed by many English native languish collogues and all the grammatical and typo errors are corrected.

3> The introduction reviews the studies of IDF, but no measurement using similar laser technique in the literature was quoted and reviewed. If no such previous measurement exists for IDF, the author may refer to other flame types in which laser technique has been used to observe the flame structure. Papers suggested for reference:

Qi, J.A., Leung, C.W., Wong, W.O. and Probert, S.D., "Temperature-field measurements of a premixed butane/air circular impinging-flame using reference-beam interferometry", Applied Energy, Vol. 83, Issue 12, pp 1307-1316, 2006.

Qi, J.A., Wong, W.O., Leung, C.W. and Yuen, D.W., "Temperature field measurement of a premixed butane/air slot laminar flame jet with Mach-Zehnder Interferometry", Applied Thermal Engineering, Vol. 28, Issue 14-15, pp 1806-1812, 2008.

- We added paragraph to highlight the techniques used in the normal diffusion flames which are related to the techniques used in the current work and we included these two references as they have a technique for a temperature measurments in flames. We updated the references list according to this modifications. 
Highlights

- The fate of spatial flame structures of methane inverse diffusion flame was monitored and investigated

- The flame structure is composed of a fuel entrainment region and an intense combustion region.

- Three types of events were common to all flames: breaks, closures and growing kernels.

- In upstream regions of the flames, the breaks were counterbalanced by flame closures. 
Experimental study of the inverse diffusion flame using high repetition rate $\mathrm{OH}$ lacetone PLIF and PIV

\author{
A.M. Elbaz ${ }^{*}{ }^{* *}$, W.L. Roberts ${ }^{*}$
}

ayman.elhagrasy@kaust.edu.sa

* Clean Combustion Research Center, King Abdullah University of Science and Technology, ** Faculty of Engineering- Materia, Helwan University, Cairo, Egypt.

\section{Abstract}

Most previous work on inverse diffusion flames (IDFs) has focused on laminar IDF emissions and the soot formation characteristics. Here, we investigate the characteristics and structure of methane IDFs using high speed planar laser-induced fluorescence (PLIF) images of $\mathrm{OH}$, particle image velocimetry (PIV), and acetone PLIF imaging for non-reacting cases. First, the flame appearance was investigated with fixed methane loading (mass flux) but with varying airflow rates, yielding a central air jet Reynolds number $(\mathrm{Re})$ of 1,000 to 6,000 (when blow-off occurs). Next, it was investigated a fixed central air jet $\mathrm{Re}$ of 4500 , but with varied methane mass flux such that the global equivalence ratio spanned 0.5 to 4 . It was observed that at $\operatorname{Re}$ smaller than 2000, the inner air jet promotes the establishment of an inverse diffusion flame surrounded by a normal diffusion flame. However, when the Re was increased to 2500, two distinct zones became apparent in the flame, a lower entrainment zone and an upper mixing and combustion zone. $10 \mathrm{KHz}$ OH-PLIF images, and 2D PIV allow the identification of the fate and spatial flame structure. Many flame features were identified and further analyzed using simple but effective image processing methods, where three types of structure in all the flames investigated here: flame holes or breaks; closures; and growing kernels. Insights about the rate of evolution of these features, the dynamics of local extinction, and the sequence of events that lead to re-ignition are reported here. In the lower entrainment zone, the occurrence of the flame 
26 break events is counterbalanced by closure events, and the edge propagation appears to control

27 the rate at which the flame holes and closures propagate. The rate of propagation of holes was

28 found to be statistically faster than the rate of closure. As the flames approach blow-off, flame

29 kernels become the main mechanism for flame re-ignition further downstream. The

30 simultaneous OH-PLIF/Stereo PIV measurements indicate that the individual breaks events

31 could be correlated to local vortical flow structure and strain rates fields. The detailed

32 measurements provide a more complete understanding of IDF flame characteristics and

33 structure than was previously possible.

\section{1. Introduction}

35 Inverse diffusion flames (IDFs) are a particular type of diffusion flame with an inner air jet

36 surrounded by an outer fuel jet, which is then surrounded by either ambient air (in practical

37 settings) or an inert gas (in some laboratory settings). Inverse diffusion flames have

38 characteristics of both ordinary diffusion and premixed flames and, hence, can exploit the

39 advantages of the low soot emissions inherent in premixed flames and the flame stability, ease

40 of fuel delivery, and operational safety inherent in diffusion flames. Because of these

41 characteristics, the feasibility of using IDFs in industrial and domestic heating processes has

42 motivated a number of experimental and numerical studies [1-17].

$43 \quad \mathrm{Wu}$ and Essenhigh's [1] group was one of the first to investigate IDFs experimentally. Six

44 different types of IDFs were mapped out and defined according to the appearance and stability

45 of the flames. The characteristics and structure of natural gas IDFs were investigated by

46 Sobiesiak and Wenzell [2]. They concluded that the inner air jet and outer fuel jets strongly

47 impact the normalized flame length. The low NOx emission characteristics of IDFs were

48 reported $[3,4]$ in relation to air staged burners. Their main conclusion was that the maximum 
49 emission index of $\mathrm{NO}_{\mathrm{x}}$ occurred at an equivalence ratio of one [3], and peaked just above the

50 outer edge of the flame tip [4]. Sze et al. [5] investigate the appearance, temperature

51 distribution, and $\mathrm{NO}_{\mathrm{x}}$ emission index of two inverse diffusion flames, one with

52 circumferentially arranged ports (CAPs) and the other with co-axial jets (CoA). They proposed

53 that the CAP, compared with CoA, was able to operate stably at a lower Reynolds number. A

54 study was conducted on the effects of the air nozzle length on pollutant emission from an IDF

55 burner with multiple fuel jets [6]. It was concluded that the short nozzle yielded a flame with a

56 more intense mixing, resulting in more complete combustion than did the long nozzle. Recently,

57 for CAPs arrangement, the effect of hydrogen percentage to LPG and air jet Reynolds number

58 on the lean stability limit were investigated [7].

59 A number of investigations on IDF sooting tendencies have also been performed [8-9],

60 where the soot forms on the outside of the flame $[8,10]$. Soot collected from IDFs is observed

61 to be tar-like with a high hydrogen content $[11,12]$. It is similar to the soot collected from under

62 ventilated normal diffusion flames [13]. Recently, the flame structure of laminar inverse

63 diffusion flames was studied by Mikofski et al. [14] to gain insight into soot formation and

64 growth during under ventilated combustion.

65 Regarding the flow field in IDFs, some authors have presumed that the velocity field of

66 IDFs is similar to that of a normal diffusion flame [15]. A schematic of the laminar flow field of

67 IDF flames was presented by Belivins et al. [13]. In this schematic, the flow field indicated

68 inward flow near the base of the flame, which was followed by slight expansion (with small

69 radial outflow) near the flame tip. Recently, the effect of the fuel-to-air velocity ratio on the

70 IDFs structure was described [16-17] using OH/PIV measurments but with an annular

71 separating distance between the air and fuel jets. In these studies, there was a separating 
72 distance between the annular fuel jet and the central air jet. This separating distance was found

73 to play a significant role in the flame structure and flame stability. On the other hand, the

74 normal diffusion flame has been investigated extensively using different measuring techniques.

75 High repetition rate OH-PLIF in a turbulent non-premixed methane flames was used to resolve

76 the turbulent flow phenomena such as vortex formation and air entrainment [18], and to

77 investigate the extinction and re-ignition in non-premixed flames with different levels of

78 oxygenation [19]. However, more insight into the flame-hole re-ignition mechanisms in

79 turbulent non-premixed flames was gained through the use of simultaneous high speed PIV/OH-

80 PLIF give $[20,21]$. The temperature fields in butane-air impinging flames and slot laminar jet

81 flame were explored and investigated using reference-beam interferometry [22, 23], where they

82 showed that the two dimensional temperature field could be calculated through the application

83 of the inverse Abel transformation.

84 In this work, we investigate the characteristics and structure of methane IDFs. Two sets of

85 experiments were conducted: the first set studied the effect of the Re of the air jet on the flame

86 structure with the fueling rate fixed; the second set investigated the effect of the fuel flow rate

87 on the flame structure at a fixed air flow rate. The flame structure was investigated using high-

88 speed OH-PLIF images of flames at $10 \mathrm{KHz}$ collected along the flame, acetone vapor PLIF

89 measurements for tracing the fuel stream under non-reaction flame conditions, as well as $2 \mathrm{D}$

90 PIV flow-field measurements. To explore the physical behind the local flame extinction and re-

91 ignition, simultaneous OH-PLIF/Stereo PIV measurement was conducted on some selected

92 flames.

93 2. Experimental setup and diagnostics

$94 \quad 2.1$. Burner and flames 
The burner geometry used in this study is shown in Fig. 1a. It was constructed using two

96 vertical concentric stainless steel tubes. The inner tube carried air and had an inside diameter of

$975.76 \mathrm{~mm}$, while the inner diameter of the outer tube was $10.8 \mathrm{~mm}$. The annular opening between

98 the tubes delivered methane. The burner was surrounded by a Pyrex shield with a side opening

99 to admit laser light and allow for imaging. The shield was used to mitigate the flame

100 instabilities that could be caused by room air currents. First, the flame appearance was

101 investigated with fixed methane loading (mass flux) but with varying airflow rates, yielding a

102 central air jet Reynolds number (Re) of 1,000 to 6,000 (when blow-off occurs). Next, it was

103 investigated a fixed central air jet Re of 4500, but with varied methane mass flux such that the

104 global equivalence ratio spanned 0.5 to 4 . The flame conditions, the global equivalence ratio

105 and their designations are given in Table 1. Among the flames appearance conditions, six were

106 selected for detailed reaction zone and mixing imaging via $10 \mathrm{kHz}$ OH-PLIF and acetone PLIF

107 respectively, and five of these were further investigated using velocity field (via $500 \mathrm{~Hz}$ PIV).

108 Three of the flames with a constant $\mathrm{Re}$ of 4500 and varying fueling rates were selected for

109 OH/acetone PLIF imaging and four were selected for PIV.

110 2.2. Planar laser-induced fluorescence (PLIF) of $\mathrm{OH}$ and acetone vapor

111 Planar laser induced fluorescence (PLIF) is carried out on OH radicals to track the spatial

112 and temporal features of a flame's structure at a $10 \mathrm{KHz}$ repetition rate. The experimental 113 configuration is illustrated in Fig. 1b. The excitation of $\mathrm{OH}$ radicals is carried out using a

114 frequency-doubled high-speed dye laser (Sirah, Cerdo-Dye) pumped with a frequency-doubled,

115 diode-pumped solid state INNOSLAB laser (Edgewave IS16II-E). The dye laser produced a

116 fundamental beam at $566 \mathrm{~nm}$ with Rhodamine 6G. This light was then frequency doubled using

117 a BBO crystal to produce ultraviolet beam at $283 \mathrm{~nm}$. The laser wavelength was tuned to 283.01 
118

119

120

121

122

123

124

125

126

127

128

129

130

131

132

133

134

135

136

137

138

139

140

nm, to pump the $\mathrm{Q}_{1}(6)$ transition of the $(1,0)$ band of the $A^{2} \Sigma \leftarrow X^{2} \Pi(1,0)$ system of $\mathrm{OH}$. The laser produced $2.4 \mathrm{~W}$ (time averaged) power at $283 \mathrm{~nm}$ at $10 \mathrm{KHz}$. The laser beam was expanded through two cylindrical lens, creating collimated sheets approximately $100 \mathrm{~mm}$ in height. It was then focused to a waist using a third cylindrical lens with a focal length of 600 $\mathrm{mm}$. The laser sheet was approximately $130 \mu \mathrm{m}$ at the center of the burner.

Fuel distribution in the flow field (under non-reacting flame conditions) was characterized by introducing acetone as a tracer to the fuel stream; the acetone was seeded by bubbling the methane through liquid acetone. To avoid fluctuations in the acetone seeding density due to temperature fluctuations, the container of acetone was immersed in a thermostatic bath (constant temperature of $350 \mathrm{~K}$ ). In this work, the acetone was excited at the same wavelength as $\mathrm{OH}$ radical (at $283 \mathrm{~nm}$ ). A seeding level lower than $10 \%$ by mass of the acetone in methane was used. This concentration was high enough to ensure a reasonable level of fluorescence yet low enough to observe the same flame dynamics as in flames without acetone.

A CMOS ICCD camera was used to capture either $\mathrm{OH}$ or acetone fluorescence. The camera was combined with appropriate filters to collect the fluorescence signals, for the OH-PLIF imaging, a good discrimination of the $\mathrm{OH}$ excitation frequency was achieved using a transmission band-pass interference filter $>80 \%$ at $310 \mathrm{~nm}$, (custom fabrication- LaserComponents $\mathrm{GmbH}$ ). Standard filters WG320 (high-pass at $320 \mathrm{~nm}$ ) and SWP606 (low-pass at $500 \mathrm{~nm}$ ) were used to acquire acetone vapor fluorescence photons. Each OH/acetone PLIF images was processed to remove (a) laser sheet inhomogeneity and (b) noise in the background from shot-to-shot laser fluctuations. The raw fluorescence image was corrected by taking into account the actual profile of the laser beam and the background signal. The sheet's profile correction was determined using an ensemble average of 10,000 individual images of the laser 
141 sheet passing through a cuvette filled with acetone placed in the center of the field of view. An

142 average was then extracted from these raw images and used to correct the fluorescence signal.

143

144

145

146

147

148

149

150

151

152

153

154

155

156

157

158

159

160

161

162

\subsection{PIV set up}

As shown in Fig. 1b, a PIV system was used to acquire 2D velocity measurements in a plane at a repetition rate of $500 \mathrm{~Hz}$, with the same field of view as the PLIF system. The PIV system consisted of a dual-cavity, diode-pumped, solid state Nd: YLF laser (LDY 300 Series) and a single CMOS camera (La Vision, image pro HS 4M); the laser was capable of delivering $35 \mathrm{~W}$ per head at $10 \mathrm{KHz}$, with a 9 ns pulse duration. With three cylindrical lenses, the laser pulses were formed into a sheet with a $0.5 \mathrm{~mm}$ waist along the burner's centerline. Both the air and fuel jets were seeded with titanium dioxide $\left(\mathrm{TiO}_{2}\right)$ particles with nominal diameters of $0.5 \mu \mathrm{m}$. Mie-scattered light from the seeding particle-laden flow was collected using a $105 \mathrm{~mm}, \mathrm{f} / 4$ objective lens (Nikon UV Micro-Nikkor) equipped with a $527 \mathrm{~nm}$ band pass filter. An adaptive multi-pass vector evaluation procedure was used, with interrogation areas ranging from 128 pixels to 24 pixels. This resulted in a spatial resolution and vector spacing of approximately 0.5 $\mathrm{mm}$ and $0.25 \mathrm{~mm}$, respectively.

\section{Results and discussion}

\subsection{Flame appearance}

The effect of the air flow rate, in terms of the exit air Re, on the flame's appearance (chemiluminescence and natural soot incandescence) for a given fuel flow rate of 1.77 slpm is shown in Fig. 2a. In conventional diffusion flames, the fuel burns with the air entrained from its surroundings and the flame is highly luminous due to soot incandescence. The introduction of a central air jet leads to the establishment of an inverse diffusion flame inside the conventional 
163 diffusion flame. At low air jet velocities $(1000 \leq \mathrm{Re}<2000)$, both flames are attached to the 164 nozzle tip, and the flames exhibit a similar appearance to a pure diffusion flame. It can be 165 observed that increasing the air jet velocity results in lifting of the IDF and shortening of the 166 outside flame. The appearance of a dual flame structure (a bluish reaction zone confined in a 167 diffusion combustion zone) occurs in flames at $\mathrm{Re}=2000$. Increasing the air jet velocity $(\mathrm{Re} \geq$ 168 2500) causes blow-off of the inner flame and establishment of an intense blue, bell-shaped structure inside the flame. Further increases in the air jet velocity ( $R e \geq 4500$ ) lead to an opening of the flame tip and eventually lead to complete flame blow-off at $\operatorname{Re}=6000$.

171 Figure $2 \mathrm{~b}$ presents examples of single-shot acetone vapor PLIF images of some of the 172 previously discussed flames with the air jet Re between 3000 and 5500. These acetone-PLIF 173 images as well as the flame appearance provide new information on IDFs. The fuel is entrained 174 immediately into the air jet at the burner exit when $\mathrm{Re} \geq 3000$, leading to a flame consisting of 175 two regions: a lower zone where the fuel is entrained toward the central air jet and an upper zone where the fuel mixes with air, leading to intense combustion. These two regions are 177 separated by a flame neck. This flame neck is surrounded by a soot ring at $\mathrm{Re}=2500$, and this 178 sooty ring gradually disappears with increasing Re number (Fig. 2a). The appearance of this sooty ring indicates non-premixed combustion of the fuel jet before entrainment into the central 180 air jet. Increasing Re from 3000 to 4000 leads to increasing fuel entrainment in the lower zone 181 of the flame, as indicated by a decrease in the length of the fuel entrainment region. However, 182 further increases in the Re number impose a higher strain rate at the end of the entrainment 183 region, which leads to less opportunity for the fuel to mix with the central air jet. This is clearly observed from the penetration of the central jet into the fuel entrainment region as the flames 185 seen from top view (Fig. 2a, at $\mathrm{Re} \geq 4500$ ), which yields a higher mixing rate further 
downstream of the jet but still within the shear layer, as indicated by acetone measurements (Fig $2 b)$.

The effect of the fuel flow rate on the flame's appearance was investigated with a constant airflow rate yielding a $\mathrm{Re}=4500$ is shown in Fig. 2c. The overall equivalence ratios for these flames range from 0.5 to 4 . As seen in this figure, the flames are mostly blue, with a ring of soot appearing when the equivalence ratio exceeds $\Phi=2.5$ (at $\Phi=2.0$, the soot ring is just visible) and becoming more obvious with increased fuel flux. For flames with an equivalence ratio of $\Phi$ $<1$, the air jet is able to penetrate through the central region of the flame, leading to a hollow flame structure. Flames with $1 \leq \Phi \leq 1.5$ are mostly blue with a thick fluctuating reaction zone that can be clearly observed at the flame's downstream central region with the early annular laminar flame confined to the central jet. This suggests that the combustion mode is primarily premixed in this central region, which is remarkable for $\Phi=1.5$ flame. Flames with an overall equivalence ratio of $\Phi>1.5$ exhibit a more intense blue color along the flame's boundaries, implying that most of the combustion occurs in the shear layer between the air and fuel jets. This is made more clear by considering the single-shot, acetone-PLIF images shown in Fig. $2 \mathrm{~d}$ of non-reacting jets at $\operatorname{Re}=4500$ with three overall equivalence ratios $(\Phi=0.89,1.5$ and 2$)$. With increased fuel flux, the effect of the fuel entrainment gradually diminishes in the early entrainment region. Image at $\Phi=2$ indicates that the annular fuel jet basically co-flows with the central air jet over a long distance of the lower part of the flame. Additionally, the flame neck, obvious at $\Phi=0.89$, disappears in the richer flame. This indicates that with the increase of the axial momentum associated with the annular fuel jet, the effect of the entrainment region in the lower part of the flame is successively reduced. 
OH-PLIF imaging was used to determine the reaction zones [24-25] in the flames studied here. Time sequences of instantaneous OH-PLIF images for flames with different air-jet Re and a constant fuel flow rate are shown in Figs. 3-5. The time interval between any two consecutive

212 images in a given row is $0.1 \mathrm{~ms}$ and the three-row composite images of OH-PLIF cover a 213 physical downstream distance of $86 \mathrm{~mm}$ along the flame centerline. Time sequences of $\mathrm{OH}-$ 214 PLIF images for flames with $\mathrm{Re}=3000$ and $3500\left(\mathrm{~F}_{3000-1.34}\right.$ and $\mathrm{F}_{3500-1.15}$; the flame designation 215 is signified by $\mathrm{F}$ with a subscript Re followed by a hyphen and the global equivalence ratio) are 216 shown in Fig. 3. The $\mathrm{OH}$ images indicate the presence of a round, short flame attached to the 217 nozzle tip. This anchored flame consumes a small fraction of the available fuel with the remainder abruptly convected towards the inner air jet and subsequently entrained by the jet

219 flow. This leads to thin $\mathrm{OH}$ filaments (laminar flame) in the upstream regions of the flame near 220 the burner exit and confines the fuel entrainment region, as shown in flame $\mathrm{F}_{3000-1.34}$ (Fig. 3a).

221 Eventually, the filaments grow toward the central region of the flame. However, in flame $\mathrm{F}_{3500-}$ 2221.15 (Fig. 3b), the annular laminar flame covers only a short portion of the flame. In these 223 flames, the $\mathrm{OH}$ zones gradually gain thickness and intensity as the downstream distance 224 increases and these zones eventually grow into the central region of the flame. In addition, the more corrugated structure of the $\mathrm{OH}$ zones and the broadening in $\mathrm{OH}$ distribution are observed 226 in this flame, suggesting a larger partial premixed region that develops into a well-mixed 227 reaction zone further downstream at this higher Re. This may be due to the higher fuel 228 entrainment rate and hence more intense fuel/air mixing, as indicated by the shorter fuel 229 entrainment region observed in the acetone-PLIF images. The greater prevalence of $\mathrm{OH}$ zones 230 in the center region of the higher Re flames compared with the lower Re flames in the upstream 231 regions is consistent with an increased rate of fuel/air mixing at the higher Re. 
Najm et al. [26] showed that the disruptions in an otherwise continuous $\mathrm{OH}$ profile agree well with local flame extinction. In most of the flames studied here, frequent local extinctions or breaks are observed (marked with red arrows in the figures). These breaks were observed to grow and lead to an enlarged gap as they propagated downstream. After the onset of extinction, as shown in Fig. 3a, the edge flames along the perimeter act as an extinction front and the breaks grow with time. The growth of these breaks does not, however, continue indefinitely; at some point, the locally extinguished regions reignite. These local extinction events are counterbalanced by the occurrence of closures, which reconnect the flame sheet and maintain stable combustion particularly in the upstream regions of the flames. Selected sequences of individual closure events are marked by the red-dashed boxes in Fig. 3b. Small flame kernels are also observed in the flames. These flame kernels tend to grow and propagate as they travel downstream where more combustible conditions are met and growth of flame kernels can be sustained, as shown in Fig. 3, where this mode of growth is illustrated by the sequences of red circles.

The OH-PLIF time sequences of flames $\mathrm{F}_{4000-1}$ and $\mathrm{F}_{4500-0.89}$ are shown in Fig. 4. For flames with $\operatorname{Re}>3500$, pockets of cold fluid are more frequently observed at flame central region. In these flames small fraction of the $\mathrm{OH}$ zone is observed in the central region of the flame, with the majority of the $\mathrm{OH}$ zone residing on the boundaries of the flame, as seen in Fig. 4b. This illustrates the penetration of the cold mixture into the center of the flame, consistent with the flame luminosities shown in Fig. 2a. This leads to an increased occurrence of disconnected $\mathrm{OH}$ zones and demonstrated by a comparison of Fig. 3 with Fig 4. These intermittent regions of $\mathrm{OH}$ tend to reconnect into a more uniform flame in the region of the second row in flame $\mathrm{F}_{4000-1}$

254 (between 25 and $50 \mathrm{~mm}$ from the nozzle tip), or further downstream in flame $\mathrm{F}_{4500-0.89}$. This 
255 reconnection mode is different from the closure mode due to edge propagation as discussed 256 earlier (occurring further upstream). These kernels initiate from the inner corrugated surfaces of 257 the annular $\mathrm{OH}$ layer and grow as they travel into regions far from the flame's centerline, where 258 local strain rates are lower and the surrounding conditions more favorable, reconnect the breaks 259 events further downstream locations. Samples of these growing kernels are given in the second 260 row of images in Fig. 4b. The occurrence of flame kernels is more frequently observed in 261 flames approaching global blow-off with higher Re. However, at flame upstream, flame hole 262 closure events are observed upstream, as shown in the first row of images in Fig. 4b, still due to 263 flame segment propagation.

The instantaneous structures of $\mathrm{OH}$ zones in flames with $\mathrm{Re} \geq 5,000$ are quite different from 265 those with comparatively lower Reynolds numbers, as seen in Fig 5. In these high Re flames, 266 the reaction zone is highly contoured, with significant fragmentation occurring. In general, the 267 structure of the $\mathrm{OH}$ zones of flames with high Re and approaching the flame blow-off limit is characterized by a large fraction of disconnected fragments, and these fragments do not exhibit the combination of premixing and diffusion in the $\mathrm{OH}$-zone structures as observed in the lower

270 Re flames. In addition, the flame kernels seem to serve as re-ignition sources in the flame 271 closure events of flames at higher Re numbers.

272 The effect of the fueling rate on the $\mathrm{OH}$-zone structures of flames with an air jet $\mathrm{Re}$ of 4,500 273 and global equivalent ratios of $0.89,1.5$ and 2 are shown in Figs. 4b, 6a and 6b, respectively. It 274 is apparent that both the equivalence ratio and the air-to-fuel jet momentum ratio strongly 275 impact the structures of the $\mathrm{OH}$ zones. As mentioned previously, flame $\mathrm{F}_{4500-0.89}$ generally 276 exhibited a corrugated and thick $\mathrm{OH}$-zone structure residing on the boundaries of the flame, 277 resulting from the penetration of the central jet into the inner region of the flame. In flame $\mathrm{F}_{4500-}$ 
278 1.5, thin $\mathrm{OH}$ zones are observed in the upstream regions of the flames near the burner exit and 279 extend nearly two-thirds of the flame length. This flame is accompanied by frequent 280 occurrences of flame breaks. Further downstream, the $\mathrm{OH}$ zone gradually thickens and 281 eventually prevails across the entire central region of the flame, as shown in Fig. 6a. These 282 well-distributed $\mathrm{OH}$ zones are consistent with the $\mathrm{OH}-z o n e$ structures seen in premixed flames, 283 suggesting a combined air-fuel mixing mode (premixed-like and pure diffusion flame-like modes) for flames with $\Phi=1.5$. These results agree with the acetone-PLIF images, where the higher fuel concentrations are confined to the early air regions leading to the disappearance of the flame necking. This indicates less mixing in the upstream region of the flame.

In flame $\mathrm{F}_{4500-2}$, comparatively thinner $\mathrm{OH}$ zones are observed on the boundaries spanning the entire imaging region, as seen in Fig. 6b. This $\mathrm{OH}$-zone distribution is consistent with $\mathrm{OH}$ distributions observed in normal diffusion flames. In this case, the acetone-PLIF image indicates the disappearance of the fuel entrainment region, which leads to less entrainment in the lower part of the flame. On the other hand, the increase in the equivalence ratio (by increasing the fueling rate) leads to an increase in the fuel jet momentum and a corresponding decrease in the air-to-fuel jet momentum ratio, which in turn reduces the shear between the air and the fuel jet. The decreased shear is expected to reduce the mixing between the fuel and air, leading to the observed thin $\mathrm{OH}$ zones.

The propagation rates of flame closures and breaks were calculated using the following approach. The principle is to use a 3 × 3 Gaussian smoothing filter on the $\mathrm{OH}$ images that are binarized by a specific threshold and then examine different threshold values to ensure that the chosen threshold has no significant impact on the determination of the size of the flame breaks 
301 (holes). This approach allows the length/size of the flame hole to be determined and, since the

302 frame rate between any two consecutive images is known, the propagation rate of the flame

303 closures and flame breaks can be determined (positive rates for closures; negative rates for

304 breaks). Selected examples of an OH-PLIF image time sequence are used to determine the rates

305 of flame breaks and flame closures and are shown in Fig. 7. The corresponding binarized OH-

306 PLIF images are shown in the bottom of the plots, and the growth and propagation rates for

307 flame breaks and closures are shown to the right of the plots.

There are many factors that may affect the correct identification of these flame break or closure events and their corresponding propagation rates. In the current study, sequences of a flame break are only considered if the flame edge extinction is vertically aligned. This therefore excludes any horizontal shift of the flame, where the flame edges are more likely to be initiated

312 from the same flame sheet. Also, any out-of-plane motion of the flame structures could result in erroneous interpretations of the $\mathrm{OH}$ images. To mitigate the impact of out-of-plane motion, two conditions must be met before the absence of an $\mathrm{OH}$ signal is deemed a flame break. First, if the structure is coming from out-of-plane motion, it is more likely to be stagnant on the plane of 316 measurement. By comparing the $\mathrm{OH}$ images containing the potential holes with the corresponding measured average axial velocity at that location, and knowing that the time between $\mathrm{OH}$ images is $0.1 \mathrm{~ms}$, the minimum threshold by which the flame structure can be shifted due to advection can be calculated. Since the velocity measurements are made at a 500 $\mathrm{Hz}$ repetition rate, relatively slow in comparison with $10 \mathrm{KHz} \mathrm{OH}$ system, the estimation of the threshold distance is based on an average flow field measurement. Figure 8 illustrates the mean velocity vector over the entire length of flame $\mathrm{F}_{3000-1.34}$ with instantaneous $\mathrm{OH}$ images 323 containing a flame hole. The mean axial velocity at the flame break location is $5.5 \mathrm{~m} / \mathrm{s}$, which 
324 corresponds to $0.55 \mathrm{~mm}$ average motion between two consecutive $\mathrm{OH}$ images. This distance is

325 then taken as a minimum threshold by which the flame structure needs to move to be considered

326 as a sequence for hole or closure calculation. The hole propagation and/or closure rate should be

327 approximately constant over a short period; if the flame structure is dominated by out-of-plane

328 motion, it will have a rate that arbitrarily changes over time. Consequently, only sequences of

329 images that have either monotonically increasing or decreasing gap widths are considered as

330 true hole and closure events, respectively. Secondly, the evaluation of flame break or closure

331 events is restricted to regions close to the burner exit, where the flow is laminarized in the

332 reaction zone due to the heat release and corresponding increase of viscosity. Here, the $\mathrm{OH}$

333 layers are thin and restricted to the reaction zones. The validity of $\mathrm{OH}$ as a reaction zone marker

334 in these lower regions has been confirmed in previous studies [27].

335 A local deviation from thermal equilibrium in which the rate of heat transport away from the

336 flame surface can exceed the rate heat release from the chemical reactions could lead to the

337 local extinction of the flame and the formation of the flame breaks. This deviation is due to the

338 turbulence flame interaction. The more frequent events of breaks and the large size of breaks,

339 negatively affect the flame stability, combustion efficiency and pollutant emissions from

340 practical points of view.

341 To investigate the possible physical phenomena taking place in the turbulence/chemistry 342 interactions, which leads to the observed breaks and closure events, simultaneous Mie scattering 343 (Stereo PIV)/ OH-PLIF imaging was conducted on flame F4500-0.89. Four components of the 344 strain rate tensor was calculated from the 2D plane velocity components. The strain rate tensor 345 was then transferred to principle coordinates to extract the two principle strain rates. The 346 maximum principle strain rate components corresponds to extensive strain, and the minimum 
347 principle component corresponds to compressive strain. The velocity vector measurments

348 showed that the third velocity component (out of plane) was not significant, especially near the

349 burner exit. Consequently, the principal strain rates computed from 2D measurement data are

350 valid near the burner exit. As shown in Fig. 8a-b, two examples of local breaks events, where

351 the disruptions in otherwise continuous $\mathrm{OH}$ fronts correlate well with the local flame front's

352 extinctions. Measurments were performed close to the burner exit where the flow is laminarized

353 in the reaction zones. In this domain, the $\mathrm{OH}$ layers are thin and restricted to the reaction zones.

354 As indicated, the break events seem to be caused by a large flow vortex breaking through the

$355 \mathrm{OH}$ fronts. This flow vortex impinges on the flame front and the extinguished flame tips are

356 seen to correspond with regions of very high extensive strains (see the zoomed-in window to the

357 top right of each plot). At extinction, the strain rates are high on the air side of the $\mathrm{OH}$ layer,

358 and there is a strong velocity component directed towards the flame front. This leads to an

359 increased rate of heat loss associated with increasing scalar dissipation rates. On the other, the

360 flow field associated with closure events or continuous $\mathrm{OH}$ layer is seen to be laminarized by

361 the higher viscosity burned gases, which provides a shield, preventing the flow vortices from

362 penetrating through the flame fronts and correspond to low strain rates (see the right part of

363 each plot). The closure event seems to be mainly due to the edge flame re-ignition mode. These

364 findings agree with some observations on the extinction of normal diffusion flames, where in

365 the normal diffusion beside extinction due to the high strain rate associated with large flow

366 vortex impinging on the flame front, sometimes the flame is extinguished at much lower strain

367 rates than the instantaneous peak strains. It is seems that the present flames are subjected to

368 such high strains for only short times and becomes more frequent as the flames approach the 369 global extinction. 
As suggested by Steinberg et al. [20], flame closure events could occur due to the propagation of flame segments, the advection of flow turbulence, or both. In the current study,

372 the effect of flow advection on the rate of flame closures could be estimated from the average

373 velocity field (as indicated for flame F3000-1.34, Fig. 9). This yields a difference of $0.4 \mathrm{~m} / \mathrm{s}$

374 between the propagation velocities upstream and downstream of the flame tips, or about $7.4 \%$

375 of the average propagation rate of flame closures $(\approx 5.4 \mathrm{~m} / \mathrm{s})$, suggesting that the effect of flow

376 advection on flame closures is small and the propagation of flame segments has a relatively

377 strong impact on flame closures.

378 Histograms of the propagation rates of flame closures and flame holes are shown in Fig. 10.

379 for flames $F_{3000-1.34}, F_{4500-0.89}$, and $F_{4500-2}$ (top row for closure and bottom for breaks). These

380 results were constructed for events occurring on the right flame edge in the image and at a

381 downstream distance of $28 \mathrm{~mm}$ from the burner exit. As shown in Fig. 10, flames with different

$382 \operatorname{Re}$ and $\Phi$ exhibit some similarity in the distribution of the flame closure propagation rate, but 383 with different mean values of this rate. For example, for the flame with $\operatorname{Re}=3000\left(\mathrm{~F}_{3000-1.34}\right)$,

384 the overall mean propagation rate of flame closures is $5.4 \mathrm{~m} / \mathrm{s}$ and the highest occurrence of 385 flame closures is at a velocity of nearly $2.5 \mathrm{~m} / \mathrm{s}$. In addition, a closure propagation rate larger 386 than $6.5 \mathrm{~m} / \mathrm{s}$ is found to occur less than $27 \%$ of the time. An increase in Re to $4500\left(\mathrm{~F}_{4500-0.89}\right)$ 387 leads to a slight decrease in the overall mean propagation rate of flame closures, to $5.1 \mathrm{~m} / \mathrm{s}$, 388 while the occurrence of the closure propagation rate larger than $6.5 \mathrm{~m} / \mathrm{s}$ also decreases to 11.4 $389 \%$. The overall mean closure propagation rate further decreases to $4.1 \mathrm{~m} / \mathrm{s}$ as the equivalence 390 increases to 2 for the flame $\mathrm{F}_{4500-2.0}$, as shown in Fig. 10c. A relatively higher occurrence of low 391 closure propagation rates is also observed for flames with $\Phi=2$, possibly due to a decreased 
392 shear between the fuel and the air, leading to a decrease in the rate of entrainment and mixing,

393 as discussed previously.

394 For flames with a $\operatorname{Re}=3000\left(\mathrm{~F}_{3000-1.34}\right)$, an overall mean hole propagation rate of $-7.9 \mathrm{~m} / \mathrm{s}$ 395 and a peak occurrence of $-2.0 \mathrm{~m} / \mathrm{s}$ are observed, as shown in Fig. 10d. The mean hole 396 propagation rate is relatively higher than that of the closure propagation rate $(\approx 5.4 \mathrm{~m} / \mathrm{s})$ and the 397 propagation rate of flame holes generally covers a wider range than that of flame closures. A 398 hole propagation rate greater than $6.5 \mathrm{~m} / \mathrm{s}$ occurs about $45 \%$ of the time, compared with less 399 than $27 \%$ of the time for flame closures. A mean hole propagation rate higher than that of the 400 closure rate is also observed for flames with increased Re (see Fig. 10e) and for flames with 401 higher equivalence ratios (see Fig. 10f). As the $\mathrm{Re}$ is increased to 4500, $\left(\mathrm{F}_{4500-0.89}\right)$, the 402 occurrence of low hole propagation rates decreases, accompanied by an increase in the mean 403 value of the hole propagation rate to $-8.2 \mathrm{~m} / \mathrm{s}$. Also, flames at $\Phi=2\left(\mathrm{~F}_{4500-2.0}\right)$, show a higher 404 probability of hole propagation rates, with an average overall hole propagation rate of about -5.4 405 $\mathrm{m} / \mathrm{s}$ (Fig. 10f). These results indicate that with increasing Re, the difference between the hole 406 propagation rate and the closure propagation rate increases. This means as the flame approach 407 the global flame extinction conditions, the difference between the hole and closure propagation 408 rates is increased, and hence the importance of flame hole size investigation.

\section{3.4. Center line velocity profiles}

410 The axial distribution of the mean centerline velocity $\left(V_{c e n}\right)$ normalized by the maximum 411 centerline velocity $\left(V_{\max }\right)$ and the corresponding velocity fluctuations $\left(V_{r m s}\right)$ with different $\operatorname{Re}$ $412\left(\mathrm{~F}_{3000-1.34}, \mathrm{~F}_{3500-1.15}, \mathrm{~F}_{4000-1.0}, \mathrm{~F}_{4500-0.89}\right.$, and $\mathrm{F}_{5500-0.8}$ under a constant fueling rate, Fig. 11a, Fig. 413 11c) and for flames at $\mathrm{Re}=4500$ with different global equivalence ratios $\left(\mathrm{F}_{4500-0.89}, \mathrm{~F}_{4500-1.5}\right.$, $414 \mathrm{~F}_{4500-2.0}$, and $\mathrm{F}_{4500-3.0}$ Fig. 11b, Fig. 11d), are shown in Fig. 11. 
As shown in Fig. 11a, the centerline velocities for these flames, are remarkably different.

416 At relatively low $\operatorname{Re}\left(\mathrm{F}_{3000-1.34}, \mathrm{~F}_{3500-1.15}\right)$, the centerline velocity displays a nearly constant value

417 and is followed by a slight decrease at an axial location between 30 to $40 \mathrm{~mm}$ from the burner

418 exit. Further downstream, the centerline velocity steadily increases, reaching a peak around 50

$419 \mathrm{~mm}$ downstream. For flames $\mathrm{F}_{4500-0.89}$ and $\mathrm{F}_{5500-0.73}$, the centerline velocity profiles are nearly

420 constant for a short axial distance from the burner exit followed by a slight but steady increase.

421 The maximum velocity is located near the same position observed for the lower Re flames, but

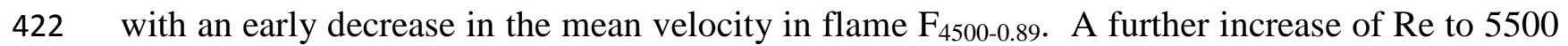

$423\left(\mathrm{~F}_{5500-0.73}\right)$ leads to a more rapid centerline decay. For these high Re number flames, the central

424 air jet was able to penetrate through the flame, resulting in the dramatically lower flame 425 temperatures.

426 With reference to the OH-PLIF images, it is expected that the velocity field will be affected

427 by the heat release rate and related to the $\mathrm{OH}$ profile. Flames with relatively low Re (Fig. 3a,

$\left.428 \mathrm{~F}_{3000-1.34}\right)$ have a higher $\mathrm{OH}$ intensity along the flame centerline than do those of higher Re (Fig.

$\left.4295 \mathrm{~b}, \mathrm{~F}_{5500-0.73}\right)$ at $\mathrm{Y}>50 \mathrm{~mm}$. This could explain the later decrease in the centerline velocity in 430 the lower Re flames, with the higher intensity (at lower Re) $\mathrm{OH}$ signal indicating an increase in 431 the temperature and the expansion of gases as they are advected from the unburnt side to the 432 burnt side. The centerline velocity fluctuations for three lower Re flames show relatively small 433 fluctuations along the flame length with a slight decrease in the magnitude of fluctuations 434 between $\mathrm{Y}=50$ to $60 \mathrm{~mm}$, followed by a relatively slight increase at the flame tip, as shown in 435 Fig. 11c. However, for flames $\mathrm{F}_{4500-0.89}$ and $\mathrm{F}_{5500-0.73}$, where the mean centerline velocities show 436 a much more pronounced decrease but at different axial locations, the region of velocity decline 437 is associated with an obvious increase in the centerline velocity fluctuations, with higher levels 
438 of fluctuations at $\mathrm{Re}=5500$. The damping of fluctuations over the entire centerline of lower $\mathrm{Re}$

439 flames, and over nearly $50 \%$ of the flame length for $\operatorname{Re}=4500$ and 5500 , is in agreement with

440 the numerical studies of jet diffusion flames by Yamashita et al. [28]. These researchers

441 concluded that the increased viscosity in the flame jet decreases the amplitude of the fluctuating

442 flame surface through the suppression of the velocity fluctuations.

443 The effect of the fueling rate can be understood from close inspection of the mean centerline

444 velocity. Figure $11 \mathrm{~b}$ shows the normalized centerline velocities for different equivalence ratios.

445 The centerline velocity of flame $\mathrm{F}_{4500-0.89}$ increases slightly to a constant value over a wide span

446 of the flame length. However, after increasing $\Phi$ to $1.5\left(\mathrm{~F}_{4500-1.5}\right)$, a slight decrease in the

447 centerline is observed, followed by a nearly constant centerline velocity region and ending with

448 a slight increase in velocity leading to its maximum velocity at flame tip. These results are in

449 agreement with the previous discussion of the $\mathrm{OH}$ images shown in Figs. 4b and 6a, where

450 increasing $\Phi$ to 1.5 affects the degree of partial premixing between the upstream fuel and air.

451 This leads to an increase in the flame temperature, sustains the flame centerline velocity over

452 the flame tip, and consequently leads to a suppression of the velocity fluctuations.

453 Increasing $\Phi$ to 2.0 delays the fuel-air mixing, and leads to a significant change in the $\mathrm{OH}$

454 distribution as shown in Fig. 6b, relative to flame $\mathrm{F}_{4500-1.5}$ (Fig. 6a). This change in $\mathrm{OH}$ 455 distribution, with no $\mathrm{OH}$ signal detected along the flame centerline, leads to a continuous 456 decline in the centerline velocity as indicated in Fig. 11b. This decline in velocity is 457 accompanied by a nearly constant low level of velocity fluctuation, with a very slight velocity 458 increase at the flame tip (Fig. 11d). A further increase in the equivalence ratio to $\Phi=3.0$ leads 459 to the same features as observed for $\Phi=2.0$, but with a steeper decrease in the centerline 460 velocity (Fig. 11b). This suggests that the degree of entrainment and hence for the flames with 
$461 \Phi$ from 1.5 to 3.0 are inversely proportional to the equivalence ratio, which means that for these

462 fuel flow rates, the fuel-air mixing is reduced and delayed with the obvious suppression in the 463 velocity fluctuations.

\section{4. Conclusions}

465 Axisymmetric inverse diffusion flames (IDFs), in which the fuel jet surrounds an inner air 466 jet, have many practical applications. High-speed images from OH-PLIF, 2D PIV, and acetone 467 PLIF were used to investigate the structure of methane IDFs. First, the flame appearance was 468 investigated with fixed methane loading (mass flux) but with varying airflow rates, yielding a 469 central air jet Reynolds number (Re) of 1,000 to 6000 (when blow-off occurs). Next, it was 470 investigated a fixed central air jet Re of 4500 , but with varied methane mass flux such that the 471 global equivalence ratio spanned 0.5 to 4 . At low Re number, an inner IDF is formed inside the 472 normal diffusion flame and a unique double flame structure is observed, where the reaction zone 473 is enveloped by an outer diffusion flame. With further increase in Re number both flame 474 appearance and acetone PLIF images demonstrated that the flames consist of two regions, a 475 lower entrainment region and a mixing and combustion upper region. In the lower entrainment 476 zone, the IDF exhibits a varying degree of partial premixing at upstream locations, depending 477 on the Re and equivalence ratio. An area of increased turbulent mixing along the shear layer of 478 the central jet then develops into a well-mixed reaction zone downstream of the flame. At lower 479 global equivalence ratios, fuel entrainment enhances fuel air mixing in this lower entrainment 480 zone, but this effect diminishes with as the equivalence ratio for increases in the high Re cases.

481 From these detailed descriptions, it is possible to conclude that the degree of entrainment of the 482 fuel jet by the air determines the extent to which the fuel is burned in the diffusion mode or 
483 premixed mode. This degree of entrainment depends on the relative momentum of the air and 484 fuel jets.

485 Although qualitative in nature, the OH-PLIF images possess sufficient spatial and temporal 486 resolution to allow quantification of the evolution of extinction and re-ignition events in these 487 flames. Three types of events common to the IDF flames studied here. The first type of event is 488 breaks that mark the initiation and further widening of gaps in an otherwise continuous $\mathrm{OH}-$ 489 PLIF profile. These breaks correspond to the well-known local extinction events in a wide 490 range of ordinary non-premixed flames approaching extinction. The second event is closure 491 events, which refer to the gradual reconnection of the extinguished edges. Particularly at 492 locations near the fuel tube, the occurrence of the flame break events is counterbalanced by 493 closure events. A correlation between break events and both the local strain rates and vortical 494 flow structures is existed. On the other hand, laminarization in the reaction zone provides an 495 effective shield preventing flow vortices from penetrating the flame front. The results show that 496 the rates of propagation of a flame hole is typically faster than that of a closure. With increasing 497 Re, the difference between hole propagation and closure propagation rates increases, which 498 increases the probability of flame blow-off. The third event is the growth of kernels, which are 499 initially small kernels of $\mathrm{OH}$ that grow with time. The occurrence of these flame kernels 500 increases as the flames approach global extinction within the flame sheet where there is 501 significant broadening of the $\mathrm{OH}$ layer. These kernels are elongated and develop into fully 502 connected flames further downstream and became the main mechanism in flame closure events 503 in regions downstream of the flame and in flames with higher Re, which approaching global 504 blow-off.

\section{Acknowledgments}


The work described in this paper was supported by the Clean Combustion Research Center

\section{References}

[1] Wu KT, Essenhigh RH. Mapping and structure of inverse diffusion flames of methane. Proceeding of the proceedings of the 20th International symposium on combustion, the combustion institute, 1984; 1925-1932.

[1] Sobiesiak A, Wenzell JC. Characteristics and structure of inverse flames of natural gas. Proceedings of the combustion Institute.2005; 30: 743-749.

[3] Partridge WP, Laurendeau NM. Nitric oxide formation by inverse diffusion flames in staged-air burners. Fuel 1995; 74: 1424-1430.

[4] Partridge WP, Reisel JR, Laurendeau NM. Laser-saturated fluorescence measurements of nitric oxide in an inverse diffusion flame. Combust. Flame 1999; 116:282-290.

[5] Sze LK, Cheung CS, Leung CW. Appearance, temperature, and NOx emission of two inverse diffusion flames with different port design. Combust. Flame 2006; 144: 237-248.

[6] Zhen HS, Choy YS, Leung CW, Cheung CS. Effects of nozzle length on flame and emission behaviors of multi-fuel-jet inverse diffusion flame burner. Applied Energy 2011; 88: 2917-2924.

[7] Miao J, Leung CW, Cheung CS. Effect of hydrogen percentage and air jet Reynolds number on fuel lean flame stability of LPG-fired inverse diffusion flame with hydrogen enrichment. Int. J. Hydrogen Energy 2014; 39(1): 602-609.

[8] Sidebotham GW, Glassman I. Flame temperature, fuel structure, and fuel concentration effects on soot formation in inverse diffusion flames. Combust. Flame 1992; 90: 269-272.

[9] Sidebotham GW, Glassman I. Effect of oxygen addition to a near-sooting ethene inverse diffusion flame. Combust. Sci. Technol. 1992; 81: 207-219.

[10] Kang KT, Hwang JY, Chung SH, Lee W. Soot zone structure and sooting limit in diffusion flames: Comparison of counter flow and co-flow flames. Combust. Flame 1997; 109 (1-2): 266-281.

[11] Arthur JP, Napier DH. Formation of carbon and related material in diffusion flames. Proc. Combust. Inst. 1955; 5: 303-316.

[12] Arthur JP, Kapur PK, Napier DH. Carbonaceous deposits from hydrocarbon diffusion flames. Nature 1952; 169: 372-373.

[13] Blevins LG, Fletcher RA, Benner BA, Steel EB, Mulholland GW. The existence of young soot in the exhaust of inverse diffusion flames. Proc. Combust. Inst. 2002; 29: 2325-2333.

[14] Mikofski MA, Williams TC, Shaddix CR, Fernandez-Pello AC, Blevins LG. Structure of laminar sooting inverse diffusion flames. Combust. Flame 2007; 149:463-478.

[15] Santoro RJ, Yeh T, Horvath TT, Semerjian HG. The transport and growth of soot particles in laminar diffusion flames Combust. Sci. Technol. 1987; 53 (2-3): 89-115.

[16] Elbaz AM, Robets WL. Flame structure of methane inverse diffusion flame. Experimental Thermal and Fluid Science 2014; 56: 23-32.

[17] Elbaz AM, Robets WL. Experimental characterization of methane inverse diffusion flame. Combust. Sci. Technol. 2014; 186: 1249-1272.

[18] Kaminski CF, Hult J, Alden M. High repetition rate planar laser induced fluorescence of OH in a turbulent non-premixed flame. Appl. Phys. B. 1999; 68: 757-760.

[19] Juddoo M, Masri AR. High-speed OH-PLIF imaging of extinction and re-ignition in non-premixed flames with various levels of oxygenation. Combust. Flame 2011; 158: 902-914.

[20] Steinberg AM, Boxx I, Arndt CM, Frank JH, Meier W. Simultaneous three-components PIV/OHPLIF measurements of a turbulent lifted, $\mathrm{C} 3 \mathrm{H} 8$-Argon jet diffusion flame at $1.5 \mathrm{KHz}$ repetition rate. Proc. Combust. Inst. 2011; 33:1663-1672. 
[21] Hult J, Meier U, Meier W, Harvey A, Kaminski CF. Experimental analysis of local extinction in a turbulent jet diffusion flame by high repetition 2-D laser techniques and multi-scalar measurments. Proc. Combust. Inst. 2005; 30:710-709.

[22] Qi JA, Leung, CW, Wong WO, Probert SD. Temperature-field measurements of a premixed butane/air circular impinging-flame using reference-beam interferometry. Applied Energy 2006; 83, Issue 12: 1307-1316.

[23] Qi JA, Wong WO, Leung CW, Yuen DW. Temperature field measurement of a premixed butane/air slot laminar flame jet with Mach-Zehnder Interferometry. Applied Thermal Engineering 2008; 28, Issue 14-15: 1806-1812.

[24] Paul PH, Dec JE. Imaging of reaction zones in hydrocarbon -air flames by use of planar laser induced fluorescence of CH. Opt. Lett. 1994; 19: 998-1000.

[25] Watson KA, Lyons KM, Donbar JM, Carter CD. Scalar and velocity field measurements in a lifted $\mathrm{CH}_{4}$-air diffusion flame. Combust. Flame 1999; 117: 257-271.

[26] Najm HN, Paul PH, Mueller CJ, Wyckoff PS. On the adequacy of certain experimental Observables as measurments of flame burning rate. Combust. Flame 1998; 113: 312-332.

[27] Bergmann V, Meier W, Wolff D, Stricker W. Application of spontaneous Raman and Rayleigh scattering and 2D LIF for the characterization of a turbulent $\mathrm{CH}_{4} / \mathrm{H}_{2} / \mathrm{N}_{2}$ jet diffusion flame Appl. Phys. B 1998; 66: 489-502

[28] Yamashita H, Kushida G, Takeno T, Twenty-fourth symposium (international) on combustion, the combustion Institute 1992; 311-316. 
Table 1: Operating conditions for inverse diffusion flames

\begin{tabular}{|c|c|c|c|c|c|c|}
\hline $\operatorname{Re}$ & $\Phi$ & Flame & $\begin{array}{c}\text { Flame } \\
\text { appearance }\end{array}$ & OH-PLIF & $\begin{array}{c}\text { Acetone- } \\
\text { PLIF }\end{array}$ & PIV \\
\hline \multicolumn{7}{|c|}{ Conditions with a fixed fuel flow rate } \\
\hline 1000 & 4 & $\mathrm{~F}_{1000-4}$ & $*$ & & & \\
\hline 1500 & 2.68 & $\mathrm{~F}_{1500-2.68}$ & $*$ & & & \\
\hline 2000 & 2.15 & $\mathrm{~F}_{2000-2.15}$ & $*$ & & & \\
\hline 2500 & 1.61 & $\mathrm{~F}_{2500-1.61}$ & $*$ & & & \\
\hline 3000 & 1.34 & $\mathrm{~F}_{3000-1.34}$ & $*$ & $*$ & $*$ & $*$ \\
\hline 3500 & 1.15 & $\mathrm{~F}_{3500-1.15}$ & $*$ & $*$ & $*$ & $*$ \\
\hline 4000 & 1 & $\mathrm{~F}_{4000-1}$ & $*$ & $*$ & $*$ & $*$ \\
\hline 4500 & 0.89 & $\mathrm{~F}_{4500-0.89}$ & $*$ & $*$ & $*$ & $*$ \\
\hline 5000 & 0.8 & $\mathrm{~F}_{5000-0.8}$ & $*$ & $*$ & $*$ & \\
\hline 5500 & 0.73 & $\mathrm{~F}_{5500-0.73}$ & $*$ & $*$ & $*$ & $*$ \\
\hline \multicolumn{7}{|c|}{ Conditions under a fixed air flow rate $(\operatorname{Re}=4500)$} \\
\hline \multirow{9}{*}{4500} & 0.5 & $\mathrm{~F}_{4500-0.5}$ & $*$ & & & \\
\hline & 0.89 & $\mathrm{~F}_{4500-0.89}$ & $*$ & $*$ & $*$ & $*$ \\
\hline & 1 & $\mathrm{~F}_{4500-1}$ & $*$ & & & \\
\hline & 1.5 & $\mathrm{~F}_{4500-1.5}$ & $*$ & $*$ & $*$ & $*$ \\
\hline & 2 & $\mathrm{~F}_{4500-2}$ & $*$ & $*$ & $*$ & $*$ \\
\hline & 2.5 & $\mathrm{~F}_{4500-2.5}$ & $*$ & & & \\
\hline & 3 & $\mathrm{~F}_{4500-3}$ & $*$ & & & $*$ \\
\hline & 3.5 & $\mathrm{~F}_{4500-3.5}$ & $*$ & & & \\
\hline & 4 & $\mathrm{~F}_{4500-4}$ & $*$ & & & \\
\hline
\end{tabular}




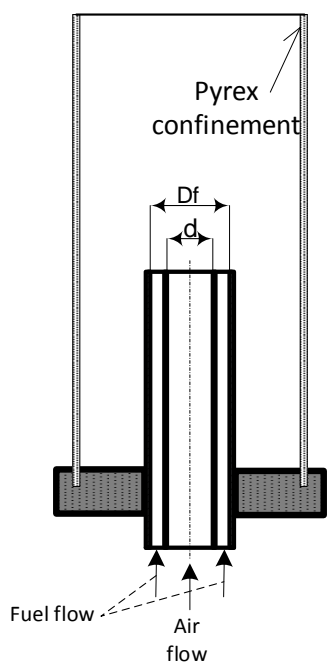

(a)

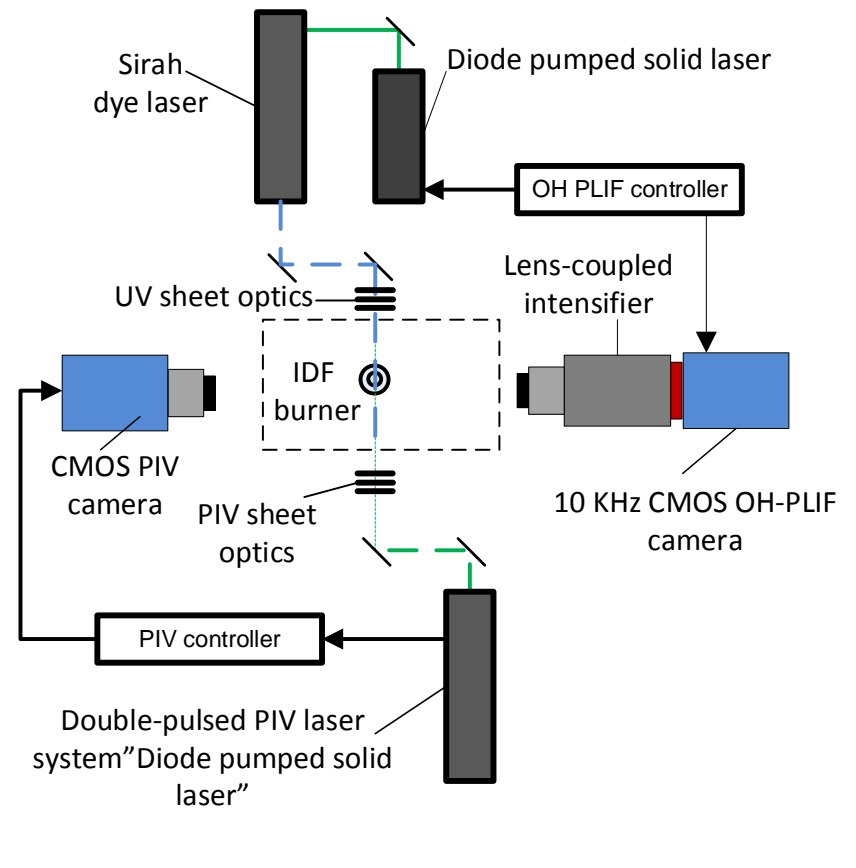

(b)

Fig. 1. (a) Schematic diagram of the IDF burner; (b) Schematic diagram of the experimental setup for

504 PIV and OH-PILF set up.

505

506

507

508

509

510

511 


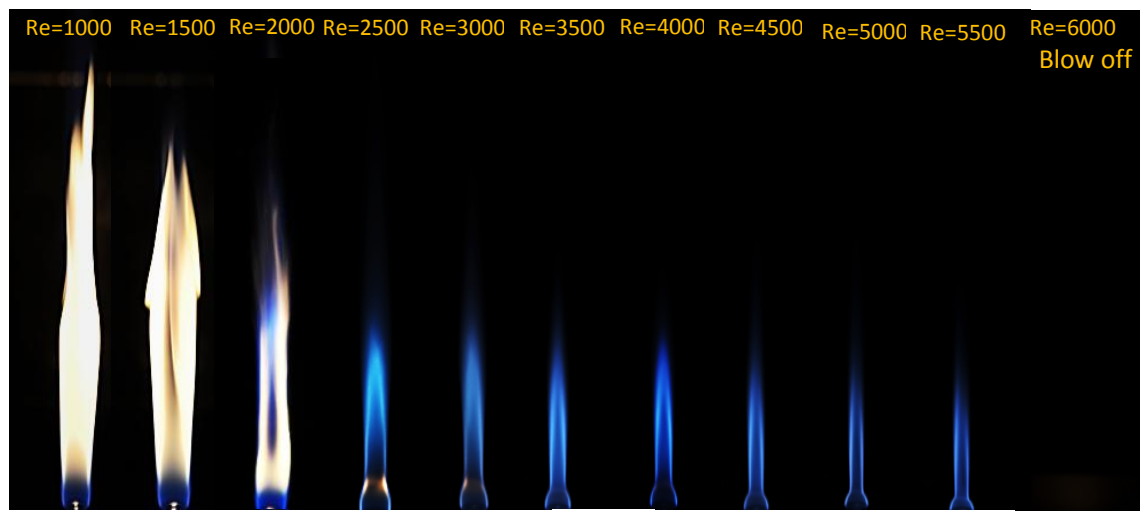

(a)

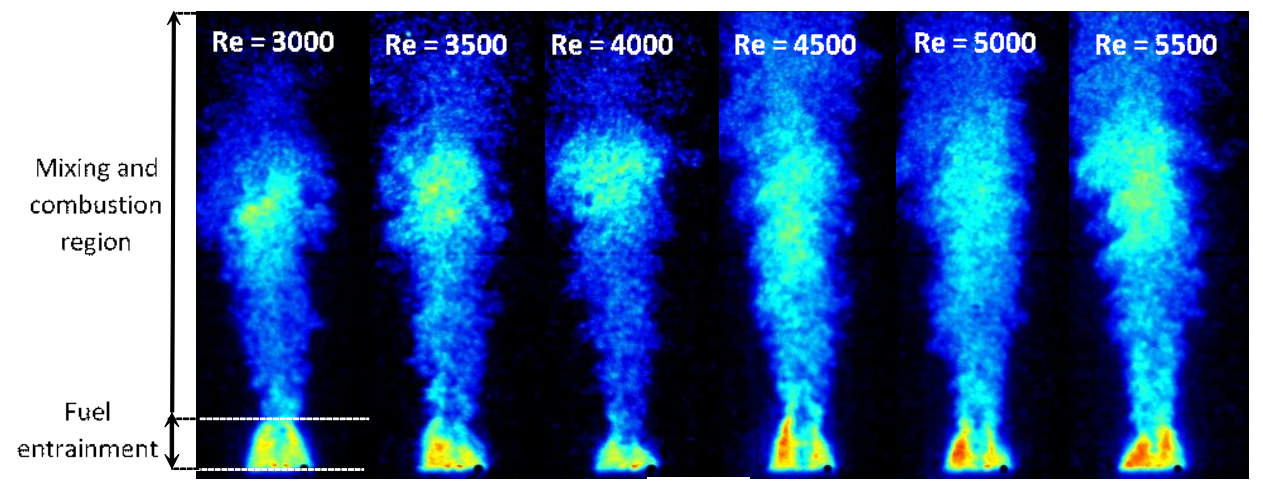

(b)

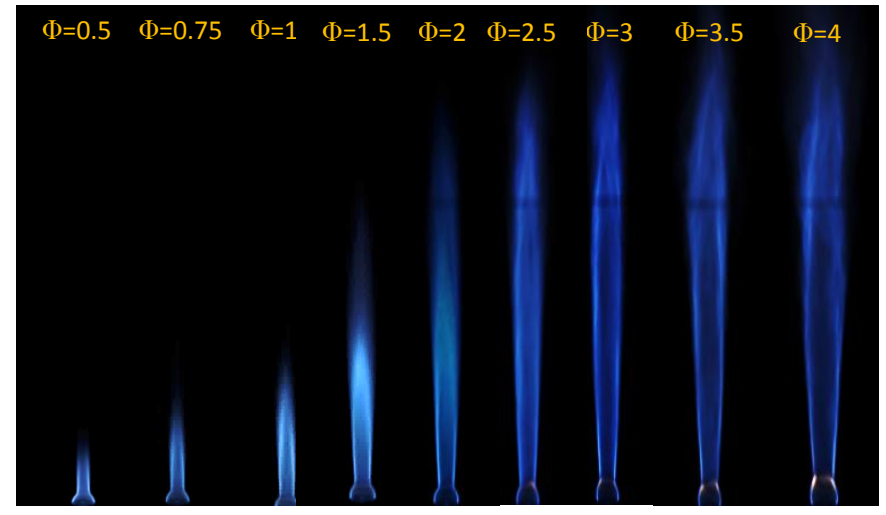

(c)

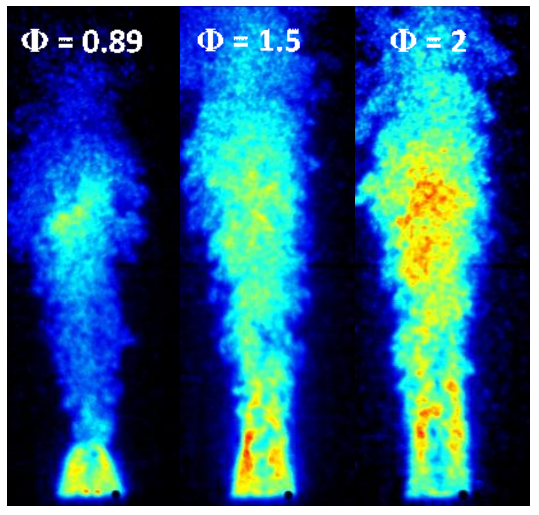

(d)

512 Fig. 2. (a) The effect of air flow rate on the appearance of IDF at a fixed fueling rate of $1.77 \mathrm{slpm}$ on 513 flame appearance; (b) Single shot acetone PLIF images under non-reacting selected flame conditions $514(3,000 \leq \operatorname{Re} \leq 5,500)$; (c) The effect of overall equivalence ratio on the flame appearance at $\mathrm{Re}=$ 515 4,500; Single shot acetone PLIF images under non-reacting three selected flame conditions $(\operatorname{Re}=4,500$, $516 \Phi=0.89,1.5$, and 2). 


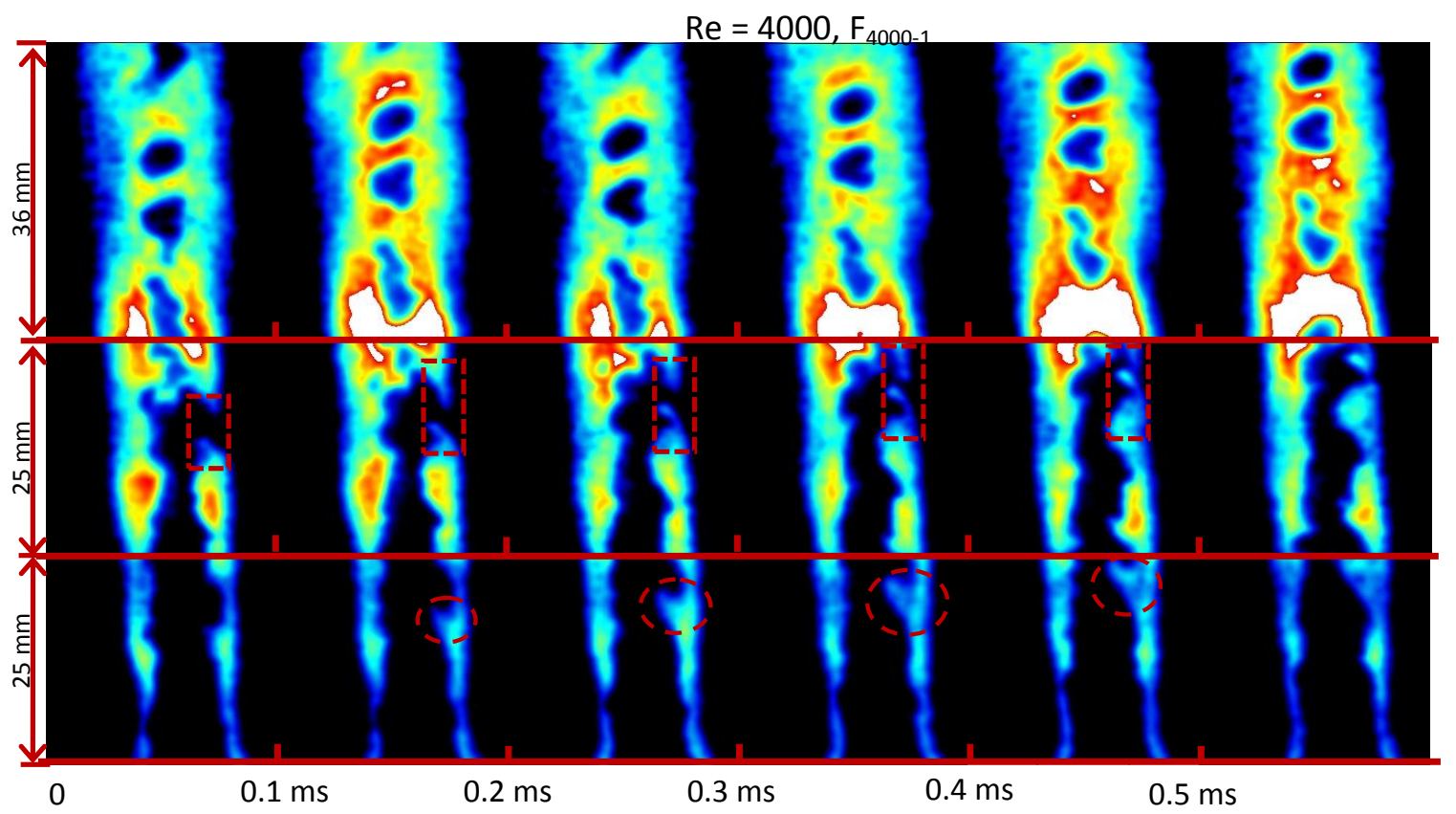

(a)

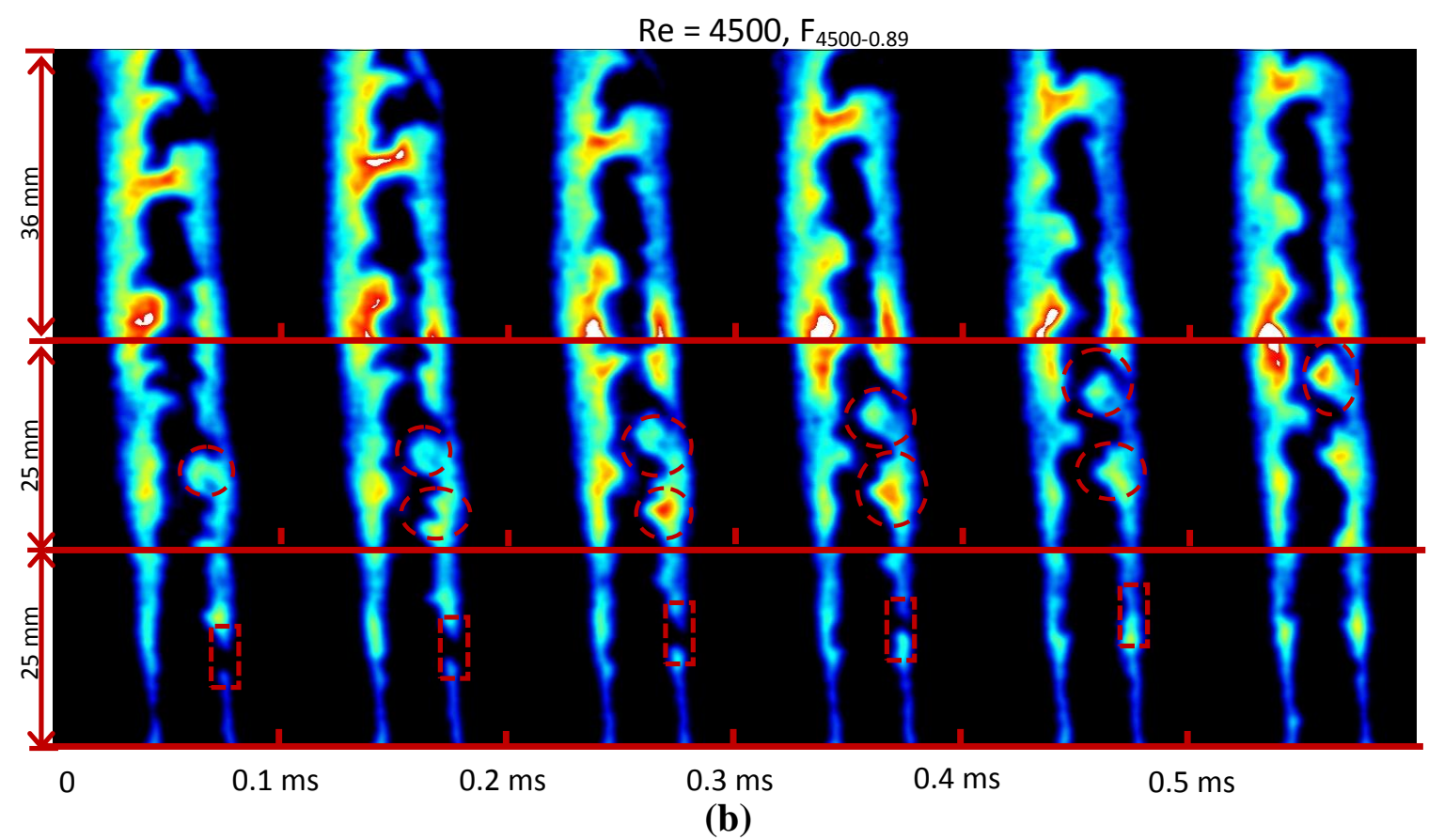

524 Fig. 4. Selected sequences of OH-PLIF images collected at various axial locations in: (a) flame $F_{4000-1}$; (b) flame

$525 \mathrm{~F}_{4500-0.89}$. Images in time sequences from left to right, with $0.1 \mathrm{~ms}$ between consecutive flames. Different rows of 526 images, the first row covers the axial distance of $0 \leq Y \leq 25 \mathrm{~mm}$; the second covers the axial distance of $25 \leq Y \leq$ $52750 \mathrm{~mm}$; and the third row covers the axial location of $50 \leq Y \leq 86 \mathrm{~mm}$. Images for different axial locations are not 528 in time sequences. Breaks, Closures, and growing kernels are indicated by arrows, squares, and dashed circles, 529 respectively. 


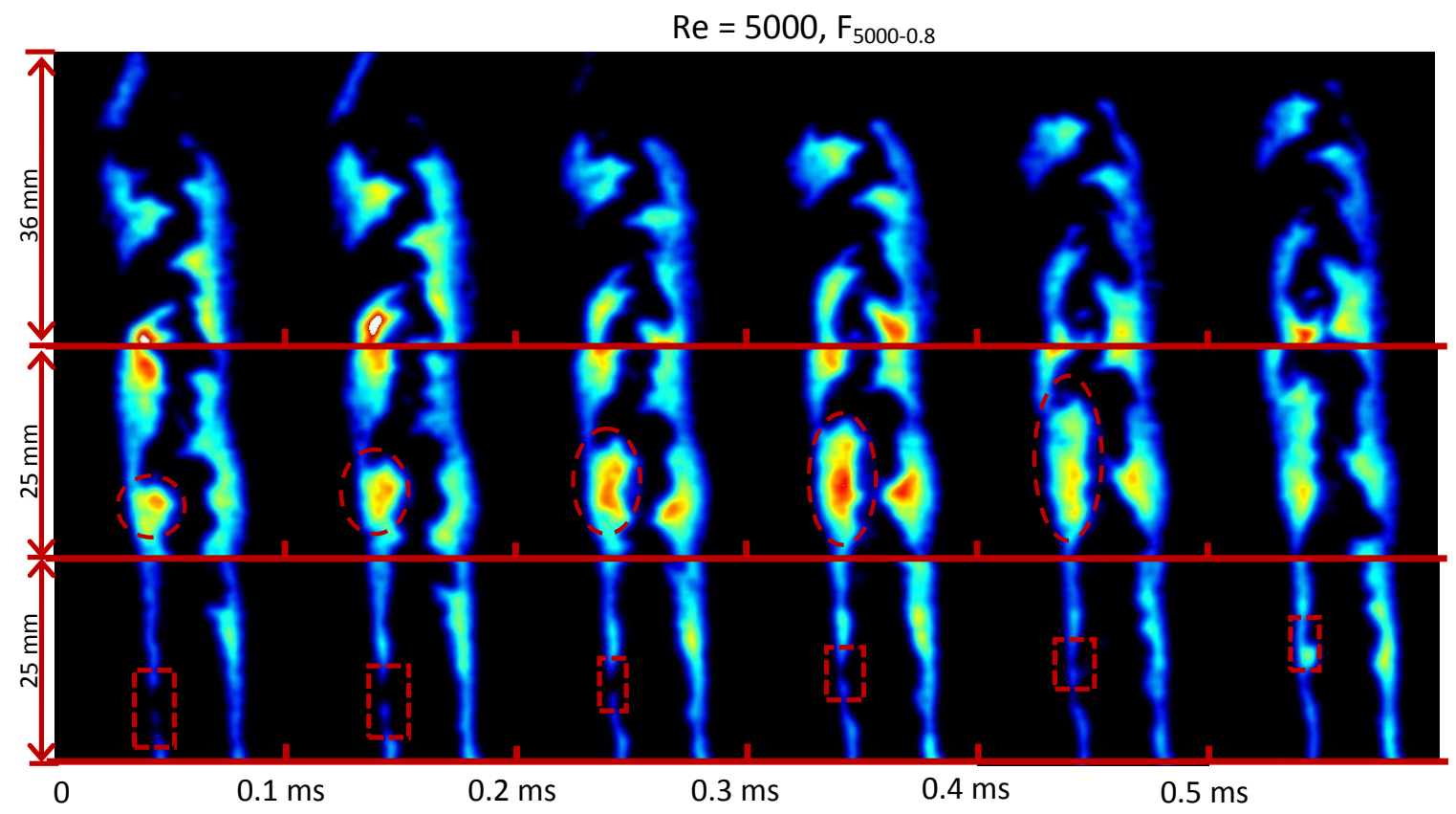

(a)

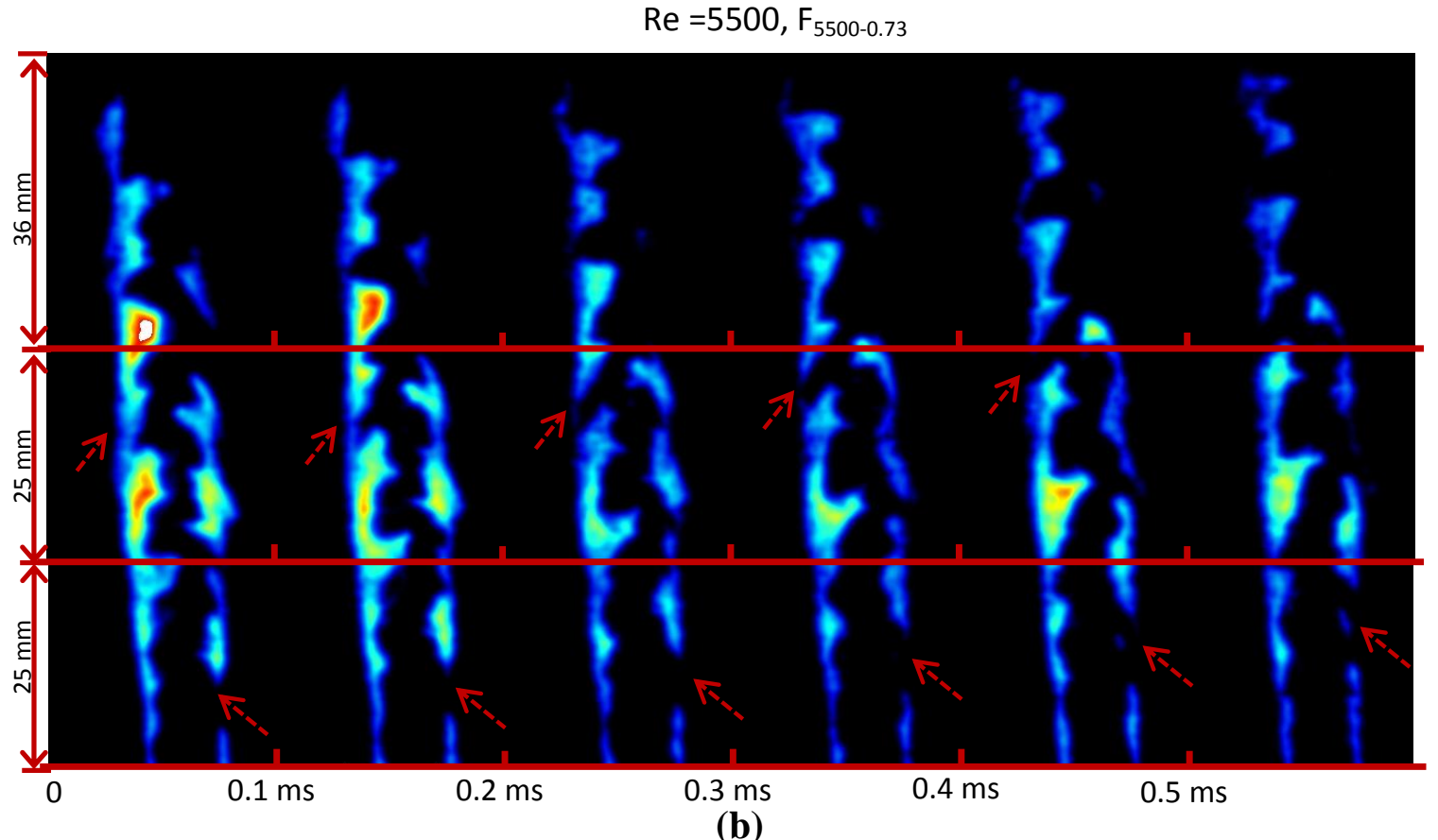

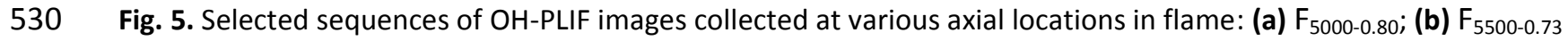
531 Images in time sequences from left to right, with $0.1 \mathrm{~ms}$ between consecutive flames. The first row covers the 532 axial distance of $0 \leq Y \leq 25 \mathrm{~mm}$; the second covers the axial distance of $25 \leq Y \leq 50 \mathrm{~mm}$; and the third row covers 533 the axial location of $50 \leq Y \leq 86 \mathrm{~mm}$. Images for different axial locations are not in time sequences. Closures and 534 growing kernels are indicated by squares and dashed circles, respectively. 


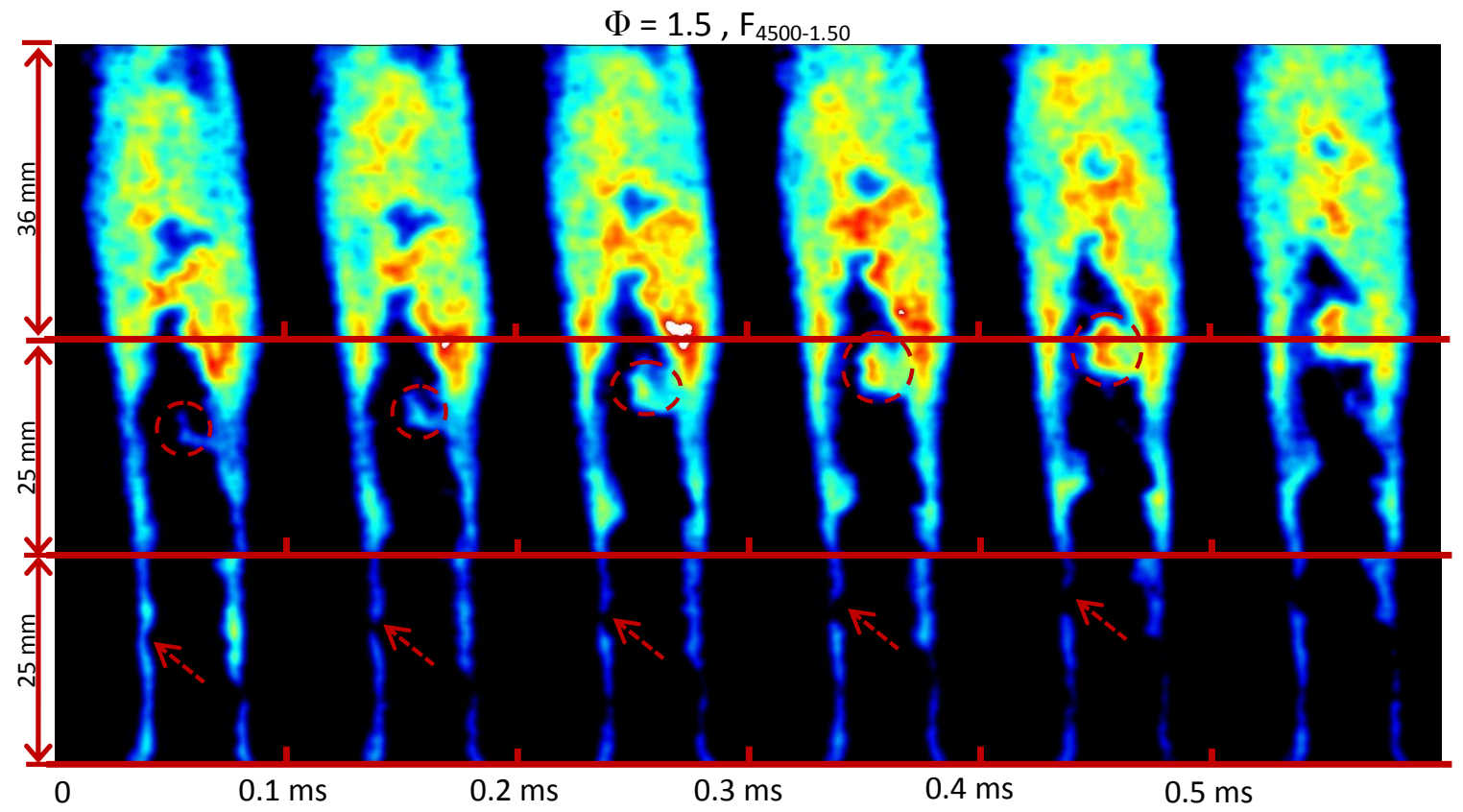

(a)

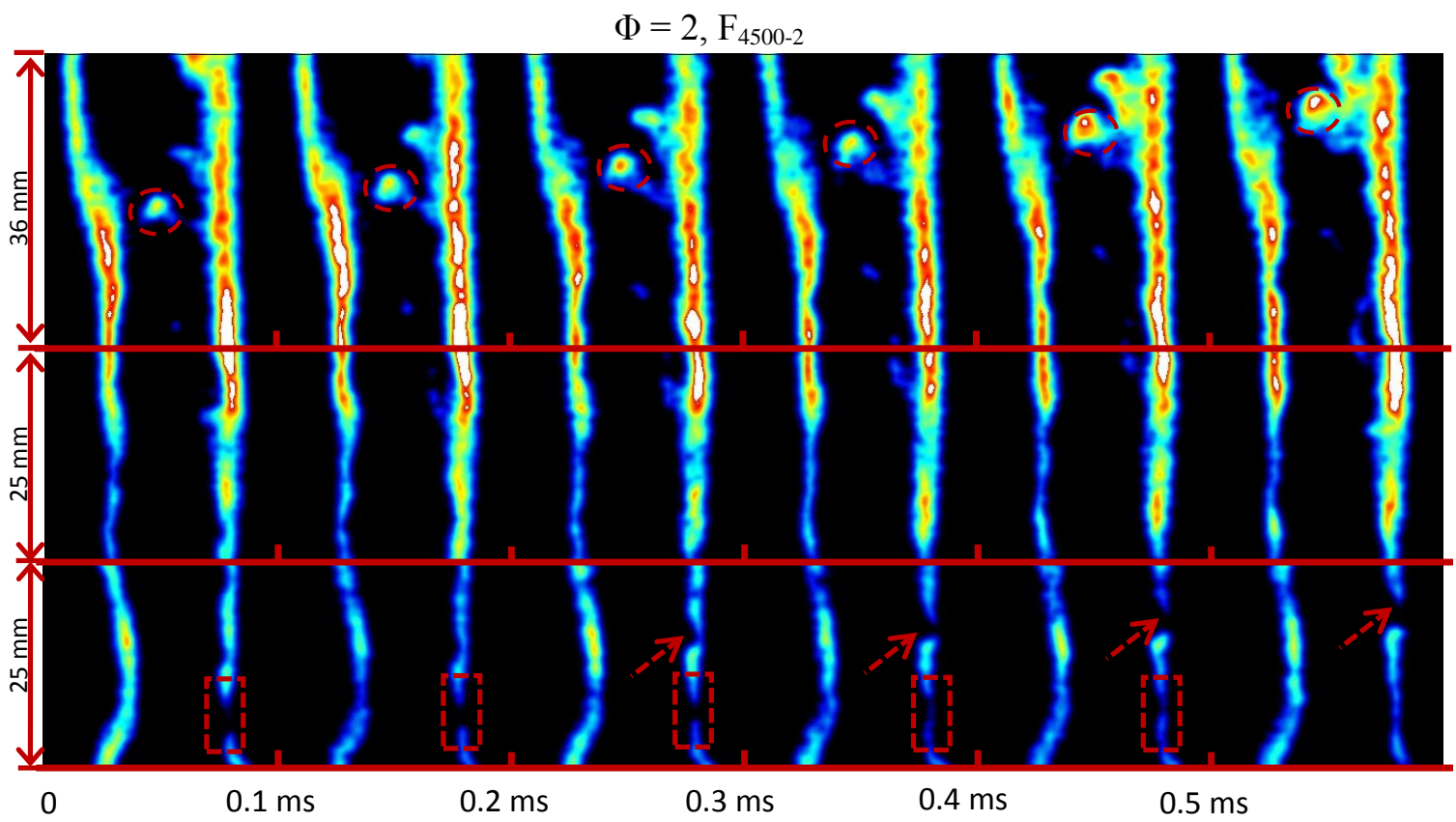

(b)

535 Fig. 6. Selected sequences of OH-PLIF images collected at various axial locations in flames: (a) $F_{4500-1.50 ;}$ (b) $F_{4500-2}$. 536 Images in time sequences from left to right, with $0.1 \mathrm{~ms}$ between consecutive flames. The first row covers the 537 axial distance of $0 \leq Y \leq 25 \mathrm{~mm}$; the second covers the axial distance of $25 \leq Y \leq 50 \mathrm{~mm}$; and the third row covers 538 the axial location of $50 \leq Y \leq 86 \mathrm{~mm}$. Images for different axial locations are not in time sequences. Breaks and 539 growing kernels are indicated by arrows and dashed circles, respectively. 

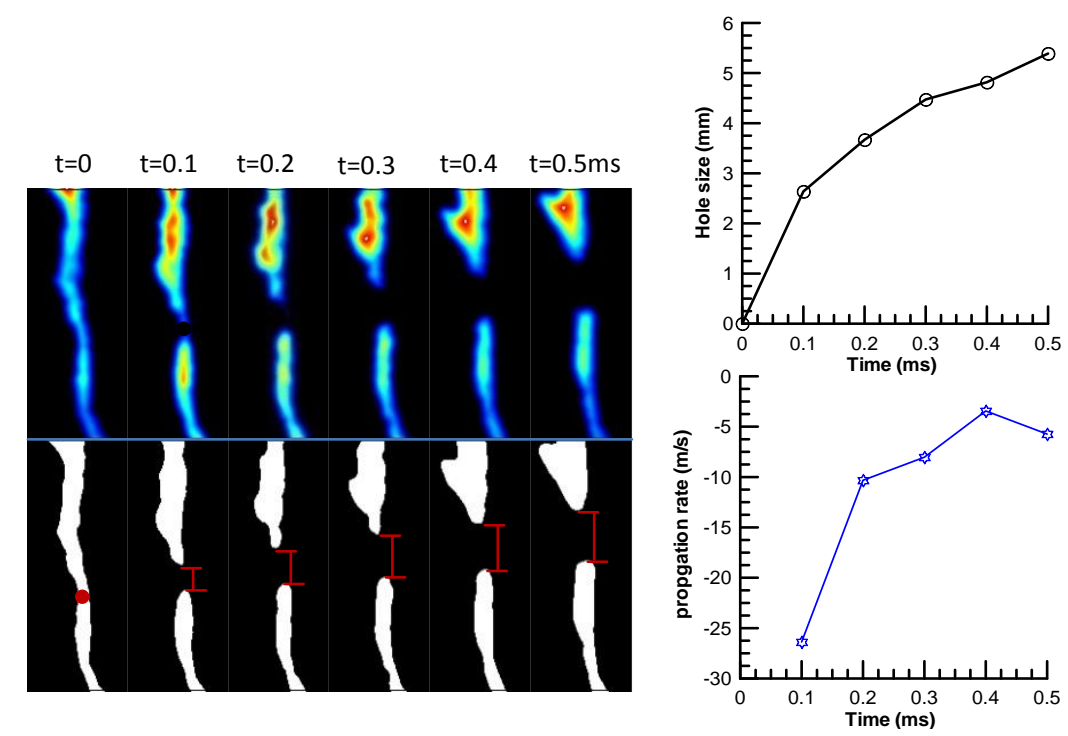

(a)
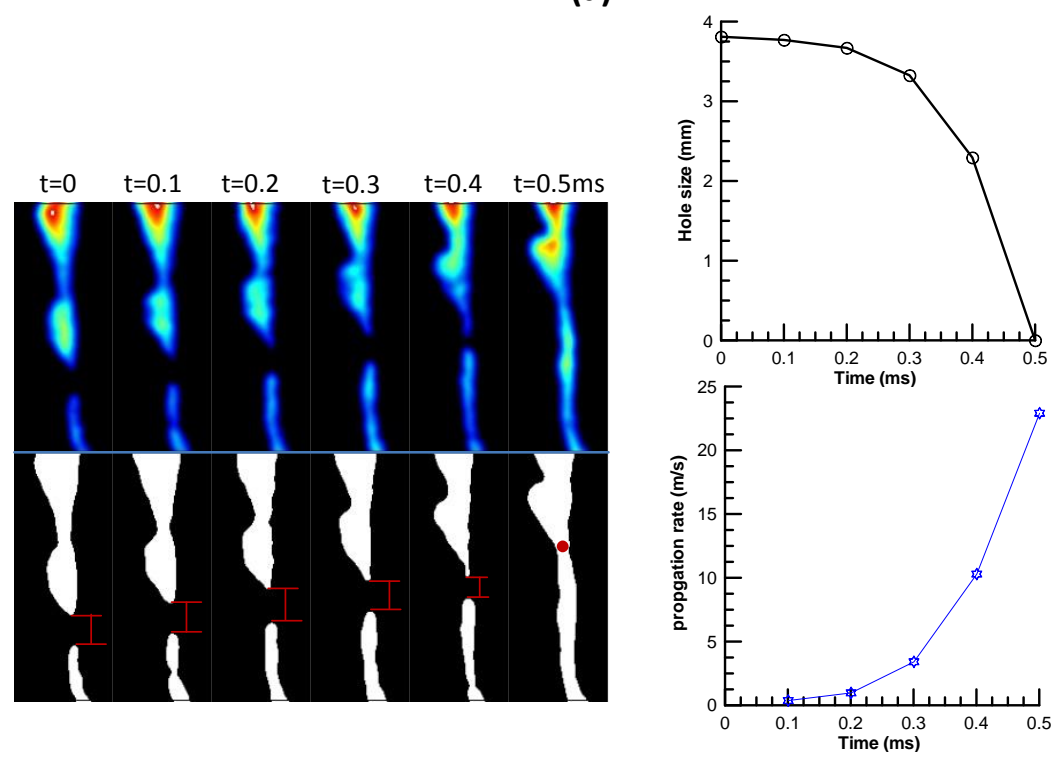

(b)

540 Fig. 7. (a) Sample images of a break event. Shown are the processed (top row) and binarised (bottom 541 row $)$ images of a flame hole growing in a $R e=3000$ flame $\left(F_{3000-1.34}\right)$. Plots on the right show the "break 542 size' and calculated 'flame propagation rate' versus time; (b) Sample images of a closureevent. Shown 543 are the processed (top row) and binarised (bottom row) images of a flame hole closing ia a $\mathrm{Re}=3500$ 544 flame $\left(F_{3000-1.15}\right)$. Plots on the right show the 'closure size' and calculated 'flame propagation rate' versus 545 time. 


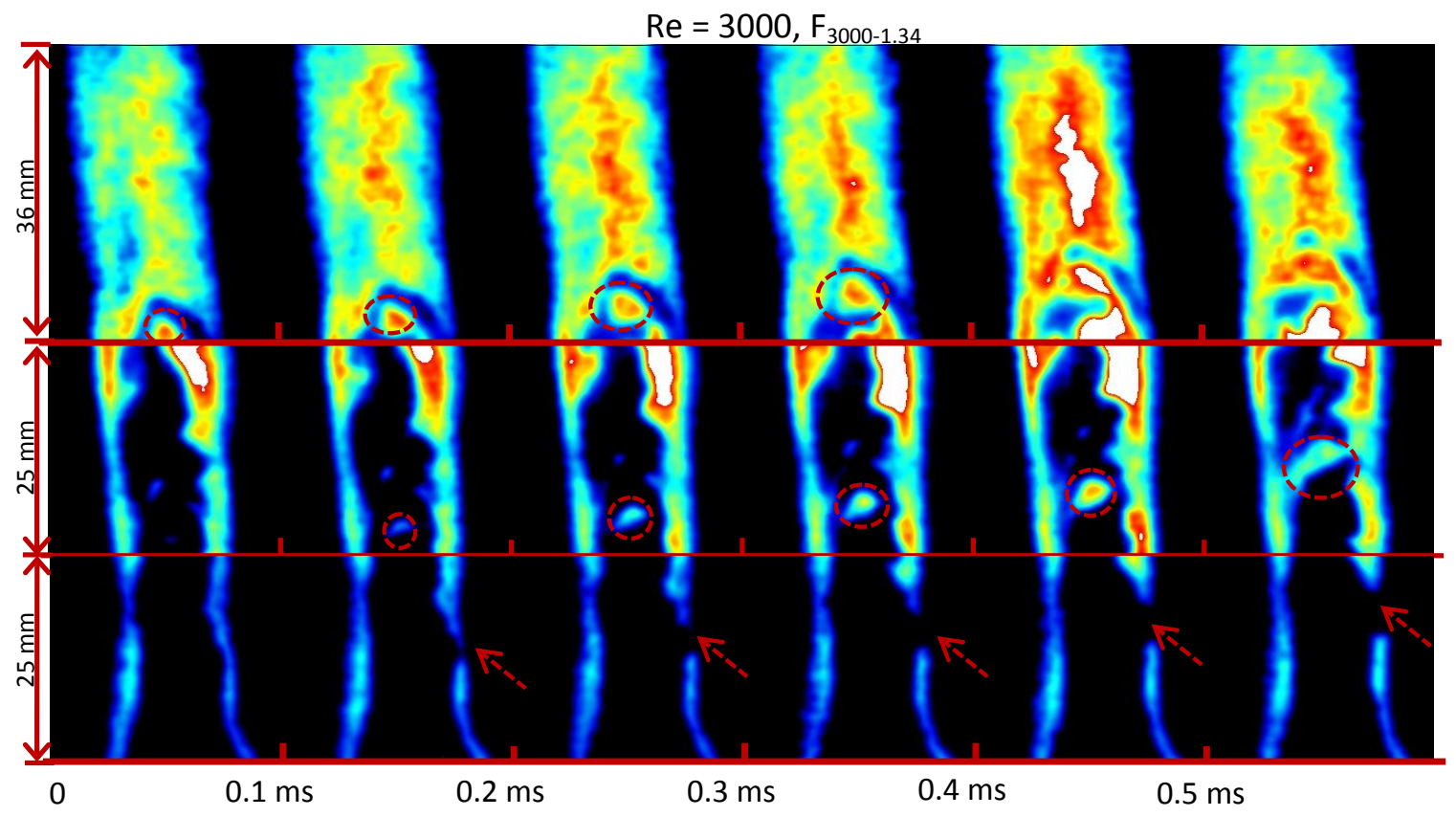

(a)

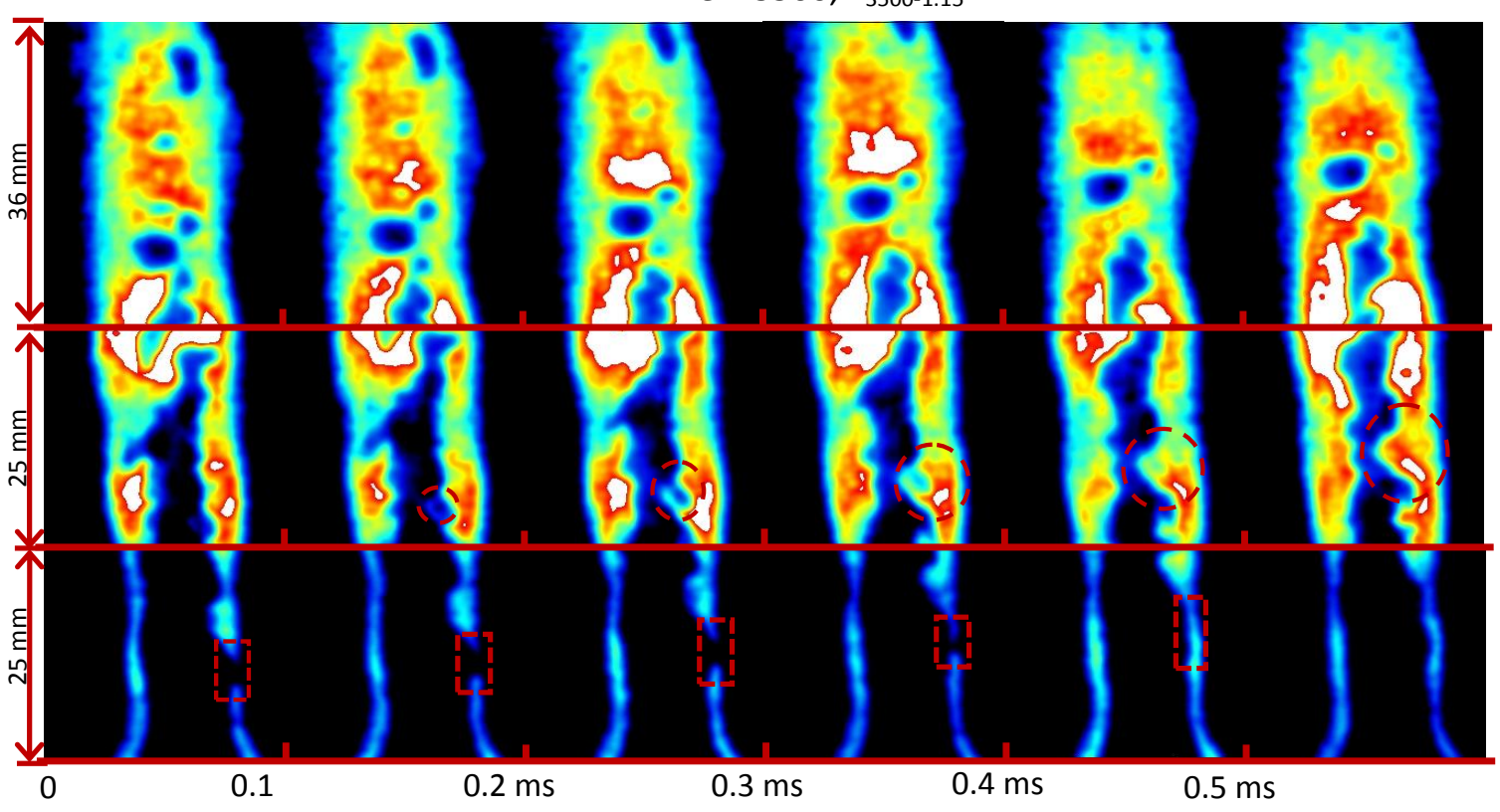

(b)

518 Fig. 3. Selected sequences of OH-PLIF images collected at various axial locations in: (a) flame $F_{3000-1.34}$; (b) flame $519 F_{3500-1.15}$. Images in time sequences from left to right, with $0.1 \mathrm{~ms}$ between consecutive flames. Different rows of 520 images, the first row covers the axial distance of $0 \leq Y \leq 25 \mathrm{~mm}$; the second covers the axial distance of $25 \leq Y \leq$ $52150 \mathrm{~mm}$; and the third row covers the axial location of $50 \leq Y \leq 86 \mathrm{~mm}$. Images for different axial locations are not 522 in time sequences. Breaks, Closures, and growing kernels are indicated by arrows, squares, and dashed circles, 523 respectively. 

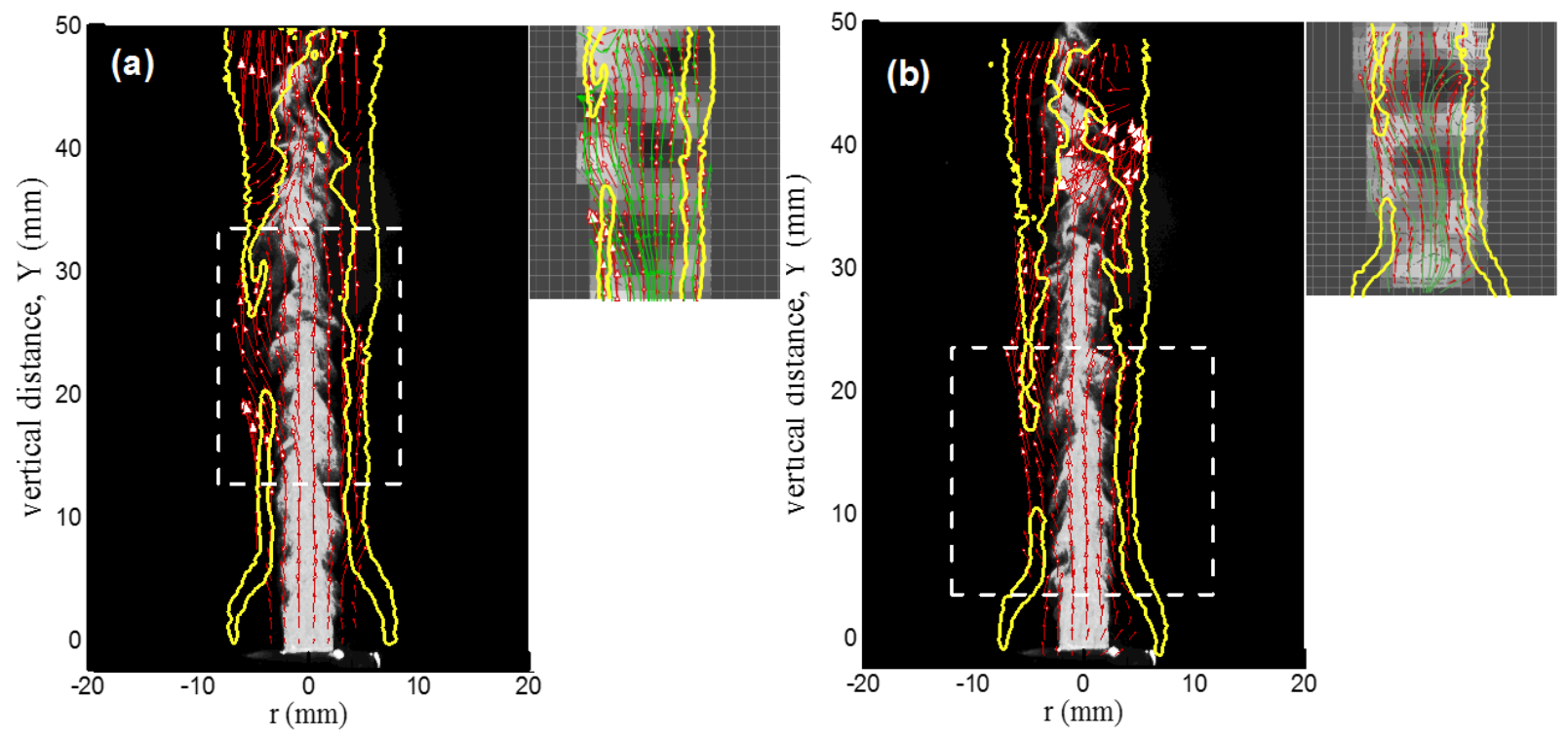

Fig. 8. Instantaneous simultaneous Mie scattering and corresponding velocity vectors/OH PLIF imaging. (a-b) Two examples of breaks events (flame $F_{4500-0.89}$ ), the gray scale is the Mie scattering and is overlaid with $\mathrm{OH}$ radicals contours (yellow lines) and velocity vectors (red vectors), the zoomed windows to the right of each plot show the maximum principles strain rates in gray scale and the corresponding $\mathrm{OH}$ contours, and velocity vectors. 
(a)

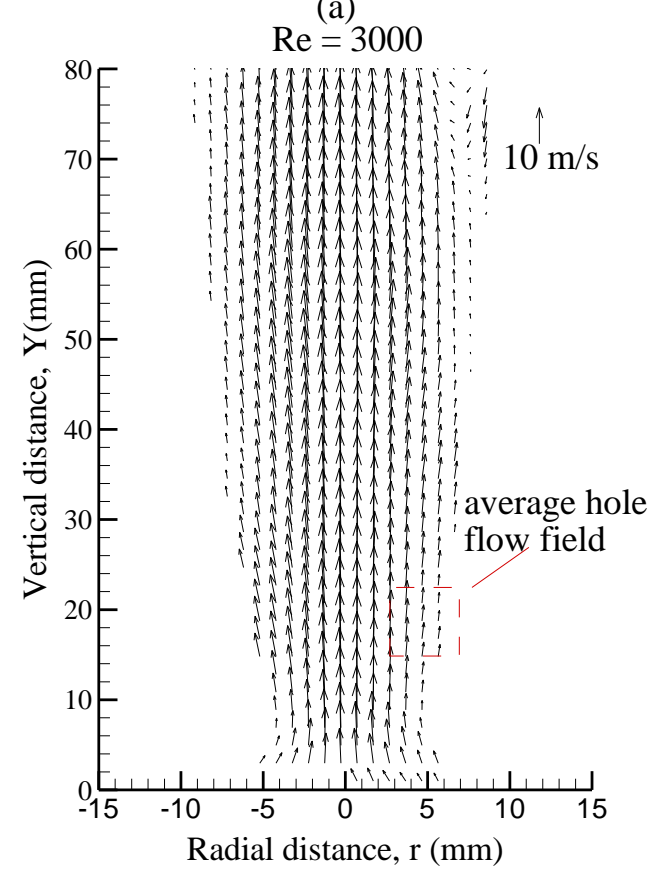

(b)

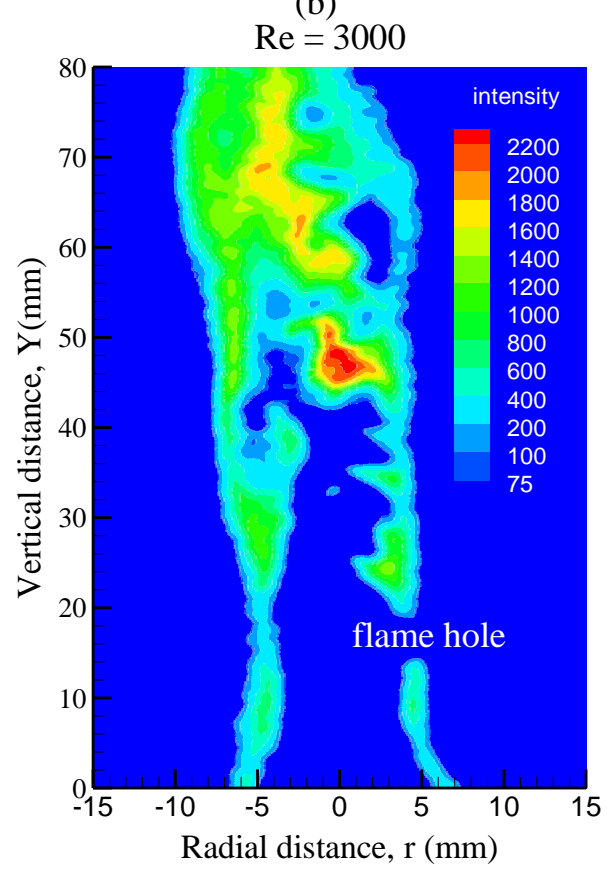

546 Fig. 9. (a) Mean velocity vectors, (alternate vectors have been removed for clarity); (b) instantaneous 547 OH-PLIF image that contains a flame hole in $\mathrm{F}_{3000-1.34}, \mathrm{Re}=3000$. 

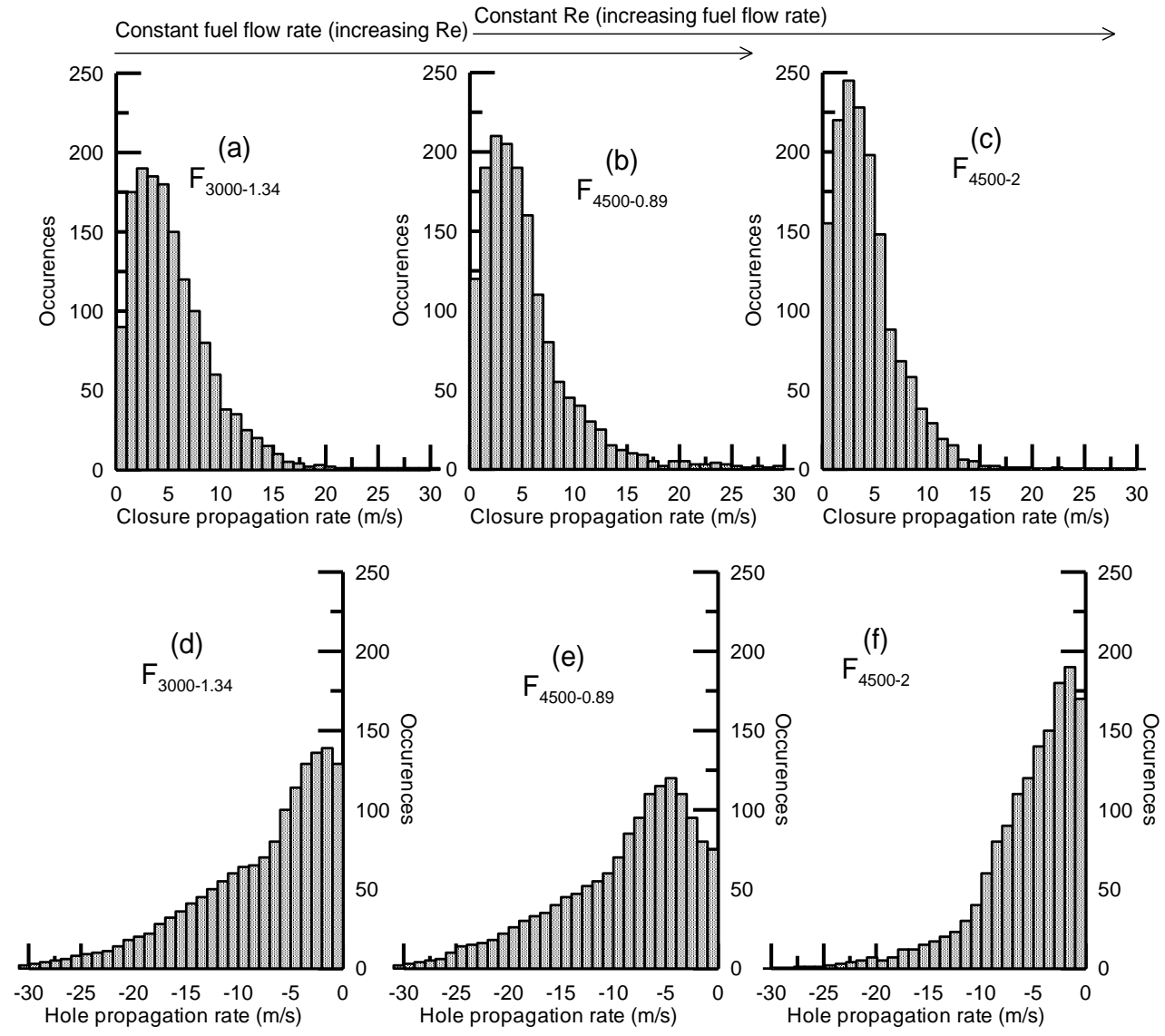

548 Fig. 10. Histogram of the number of occurrences/1500 in relation to rates of closures and holes for 549 flames of $\operatorname{Re}=3000,4500\left(F_{3000-1.34}, F_{4500-0.89}\right.$, constant fuel flow rate $)$ and with flame at $\operatorname{Re}=4500-\Phi=2$ $550\left(\mathrm{~F}_{4500-2}\right)$. The closures are defined as positive propagation rates, while the holes are defined as negative 551 propagation rates. 

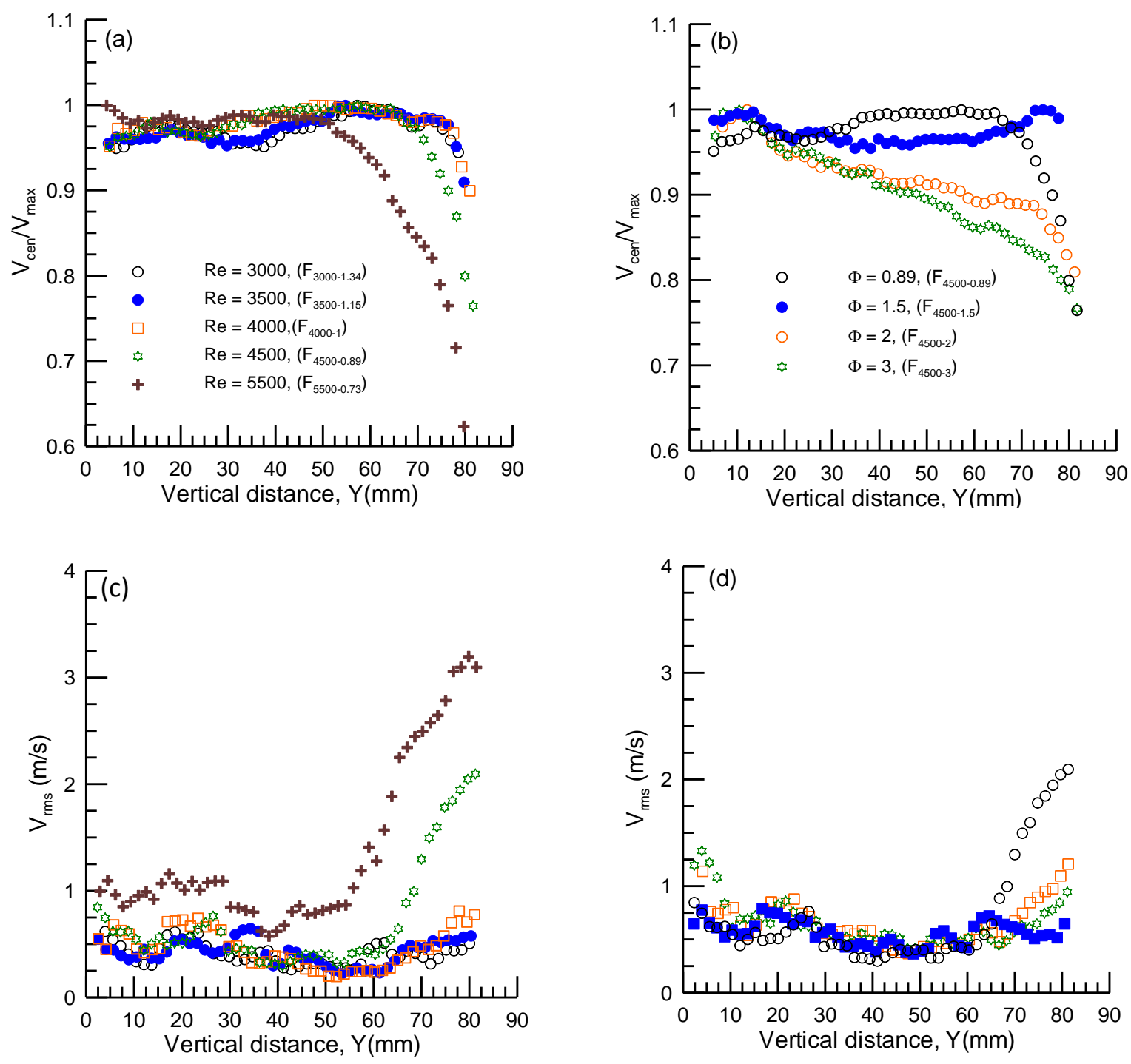

Fig. 11. The mean centerline velocity as a function of the axial distance normalized by the maximum centerline velocity for (a) $\operatorname{Re}=3000,3500,4000,4500,5500$ flames (with constant fuel flow rates, $F_{3000}$ 1.34, $F_{3500-1.15}, F_{4000-1}, F_{4500-0.89}, F_{5500-0.73}$ ), (b) for $\Phi=0.89,1.5$, 2, and 3 flames (Re is kept constant at 4500, presented in (c) and (d), respectively. 


\section{Responses to Technical Check Results}

Fuel Journal

Manuscript entitled: High-speed imaging of $\mathrm{OH}$ and acetone PLIF reveals the structure of methane inverse diffusion flames

1) Line numbering is mandatory. Please number all the lines in the Manuscript continuously.

$\checkmark$ We added line numbering.

2) Abbreviations should be defined the first time they are used. For example, Please check the requirement for the abbreviation "PLIF" in the abstract.

$\checkmark$ We defined all the abbreviations with first time they are used.

2) All pages should be numbered sequentially.

$\checkmark \quad$ All the pages now are numbered sequentially.

3) Do you intend to have your figures printed in color? If yes, you will have to pay for color printing. If not, submit black and white figures as well, so that the reviews and editor can judge the quality of figures that will be published.

$\checkmark$ Yes we intend to have the figures printed in color, and this is to confirm that we will pay for color printing. So we only submitted the color figures.

5) Original high-quality research papers should be preferably around 20 and certainly no more than 30 double line spaced manuscript pages, including tables and illustrations.

$\checkmark$ The paper now is in a double line spaced format and within the required number of pages.

The manuscript has been resubmitted to your journal. We look forward to your positive response.

Sincerely,

Ayman Elbaz 